\title{
The Physical and Mathematical Modelling of Continuous Casting Tundish Systems
}

\author{
Dipak MAZUMDAR and Roderick I. L. GUTHRIE ${ }^{1)}$
}

Department of Materials \& Metallurgical Engineering, Indian Institute of Technology, Kanpur, India. 1) McGill Metals Processing Centre, McGill University, Montreal, Canada.

(Received on January 22, 1999; accepted in final form on March 8, 1999)

\begin{abstract}
Considerable efforts have been made in academia and industry over the last two decades to fully exploit and enhance the metallurgical performance of continuous casting tundish systems. Towards these goals, numerous physical and mathematical modelling studies embodying both industrial and water model tundishes have been carried out and reported in the literature. Based on an extensive literature search, we now present a summary, discussion and analysis of these. For the sake of convenience and clarity of presentation, the studies have been categorised into three major groups: (1) physical modelling (2) mathematical modelling and (3) combined physical and mathematical modelling. In each of these categories, a great number of publications on various aspects of tundish metallurgy, such as, modelling criteria, turbulent fluid flow, residence time distributions (RTD), inclusion transport and separation, heat loss and temperature drop, grade transition and intermixing, etc. have been reported. These works have lead to considerable improvements in our understanding of the various transport processes (viz, RTD, inclusion float out, thermal energy transport, etc.) associated with tundish operations. Comprehensive and sufficiently reliable mathematical models are also currently available and these also allow one to carry out full scale predictions and useful engineering design and process calculations. None the less, certain obscurities and uncertainties remain. These are reviewed together with suggestions of areas where further research is needed.
\end{abstract}

KEY WORDS: review; continuous casting tundish; physical modelling; mathematical modelling; turbulent fluid flow; residence time distributions; inclusion separation; heat loss; intermixing.

\section{Introduction}

In the continuous casting of steel, a tundish traditionally refers to an intermediate vessel placed between the ladle and the mould, designed to supply and distribute molten steel to different continuous casting moulds, at a near constant rate. More importantly, with continuing emphasis on superior steel quality, it is now increasingly clear that a continuous casting tundish has a far more important function as a continuous reactor than originally envisaged. Thus, in recent years, the continuous casting tundish has evolved into a useful reactor for liquid steel refining. As such, it now has important roles to play over and above its traditional role as a buffer, or steel distribution, vessel. Thus, a modern day steelmaking tundish is designed to provide maximum opportunity for carrying out various metallurgical operations such as inclusion separation, flotation, alloy trimming of steel, calcium doped inclusion modification, superheat control, thermal and particulate homogenisation. These unit operations have gained considerable importance owing to their present day relevance, leading to the development of a separate area of secondary refining of steel, referred to as "tundish metallurgy".

During the past thirty years or so, the share of steel produced via the continuous casting route has increased remarkably. Associated with this increase in production, finished steel has been subjected to tighter specification control (of both composition and cleanliness) to meet the diverse requirements of a challenging market place. Thus, significant efforts have been made by researchers around the globe during the past two decades or so, to fully exploit and enhance the potential of continuous casting tundish as a molten steel refining vessel. Accordingly, research activities in the area of "tundish metallurgy" have resulted in a large number of investigations, both theoretical and experimental, covering many diverse facets of molten steel processing in tundishes.

Since tundish metallurgy, in recent years, is becoming such an integral component of clean steel production technology, research activities concerning the associated theoretical and applied aspects have naturally lead to a large number of publications. For example, the open literature now comprises a book, ${ }^{1)}$ monographs, ${ }^{2.3}$ ) reviews ${ }^{4-9)}$ and many research articles dealing with widely varying aspects of "tundish metallurgy". Indeed, the volume of literature on tundish metallurgy is quite huge and diverse. Summarising every study requires covering an extremely vast area of research, and would appear to be beyond the scope of a single, exhaustive, up-to-date review. As illustrated in Fig. 1, it has been decided for the purpose of the present work, to classify 


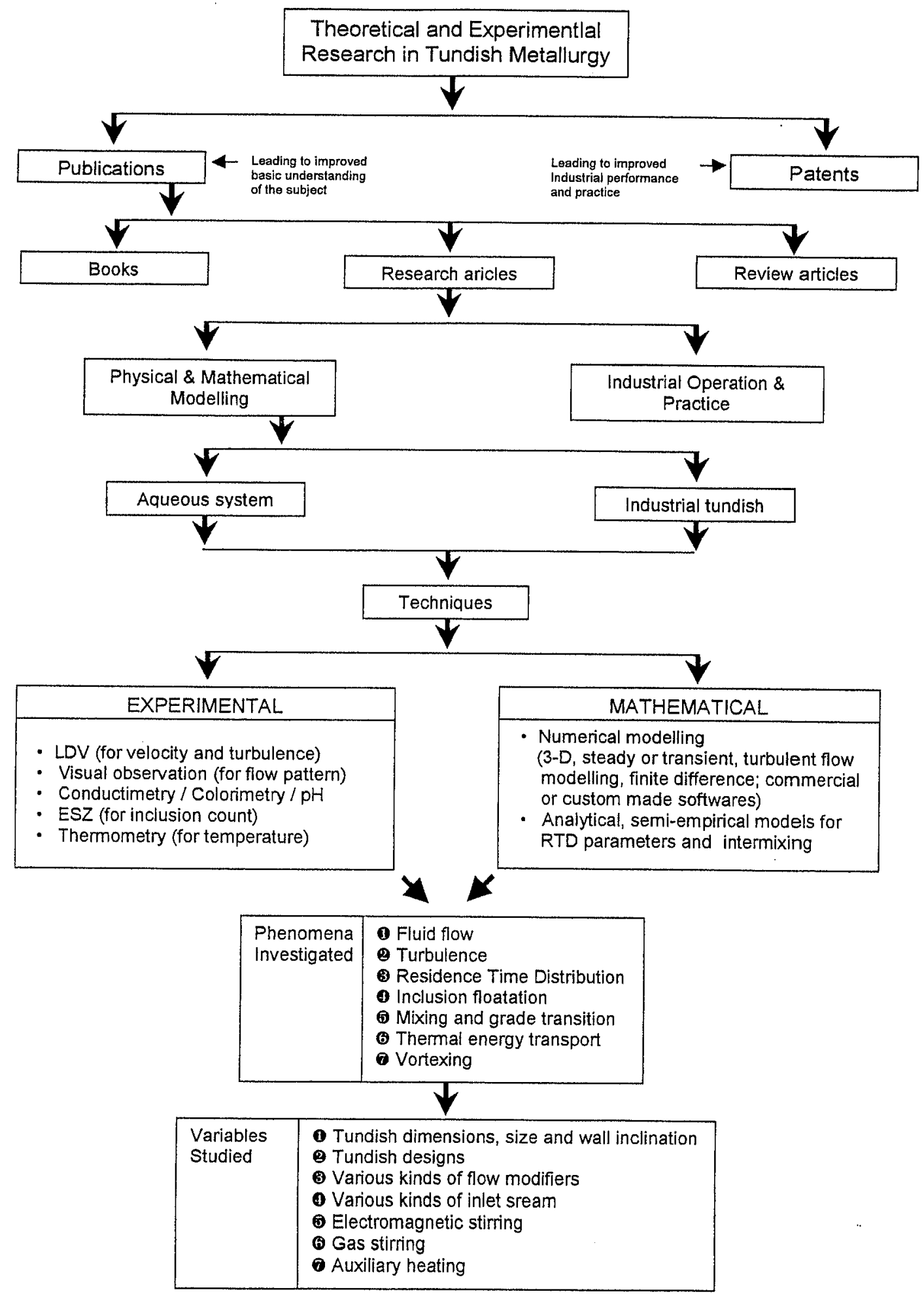

Fig. 1. A summary of the outcome of theoretical and experimental research in tundish metallurgy.

the published research articles under two broad categories: (i) physical and mathematical modelling and (ii) industrial operations and practice. As such, we present a review of research work on an important, but specific, area of tundish metallurgy, this being the physical and mathematical modelling of continuous casting tundish systems.

Consequently, the purpose of the present work has been to bring together the results of a large number of investigations in this area, and to present a compre- hensive review and critique. In the subsequent sections therefore, laboratory, pilot scale and mathematical modelling studies of continuous casting tundish systems, are summarised. For the sake of convenience, these investigations have been categorised into three major groups, e.g., (i) physical modelling studies, (ii) mathematical modelling studies and (iii) combined physical and mathematical modelling studies. 

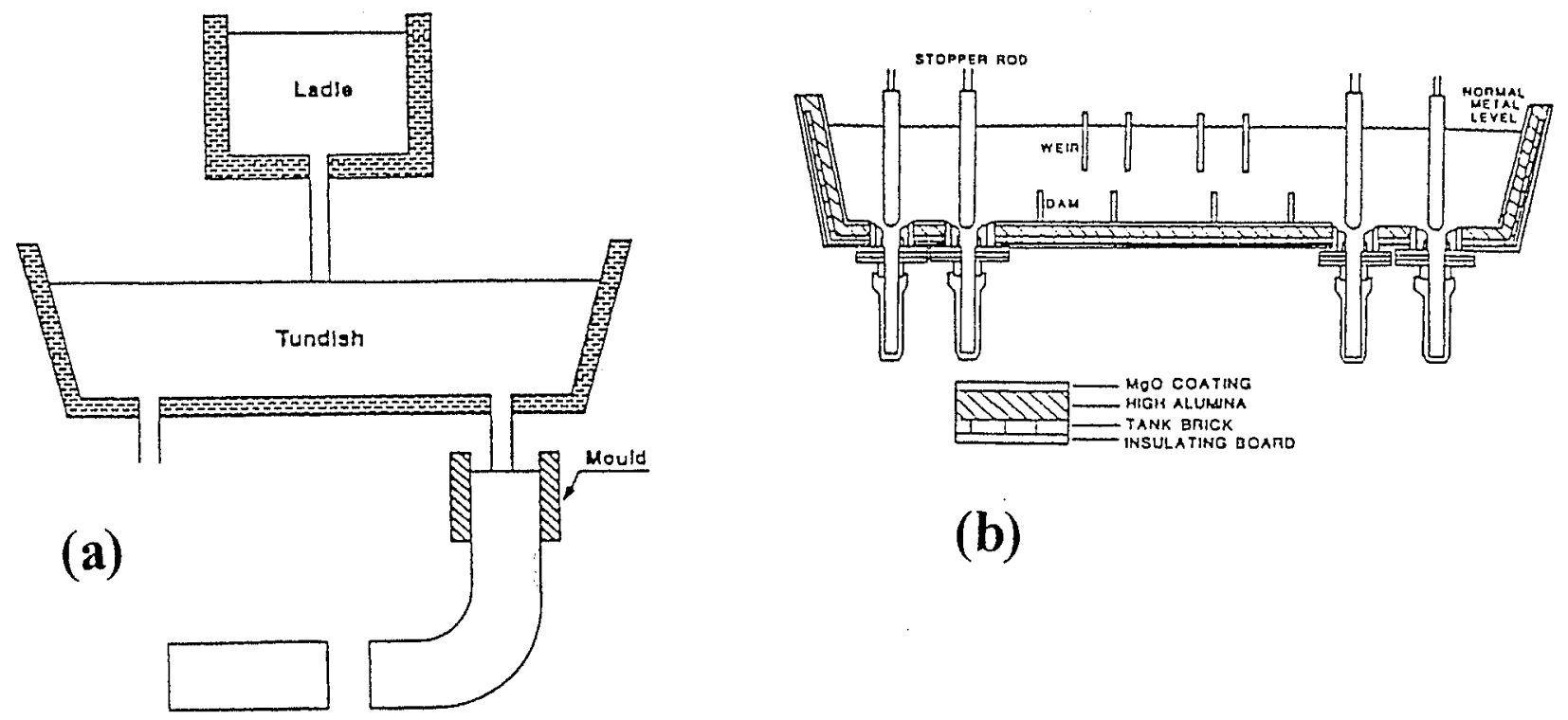

(b)

Fig. 2. Schematics of (a) the ladle-tundish-mould arrangement of relevance to continuous casting of steel ${ }^{52)}$ and (b) the continuous casting tundish. ${ }^{12}$ )

\section{Physical Modelling studies}

Figure 2(a) provides a schematic of the ladle-tundishmould arrangement of relevance to the continuous casting of steel. Similarly, in Fig. 2(b), a more detailed illustration of a typical four strand industrial tundish is shown. There, molten steel from the ladle is fed into a tundish which distributes the liquid steel between the four strands of the continuous casting machine. Except for a short period of time during a ladle change, the tundish is operated at a practically constant bath depth, such that the ferro-static head of liquid remains dynamically steady, thereby providing a constant flow of molten steel into the mould below. In the process of transferring molten steel from the ladle to the moulds, liquid steel passing through the tundish remains, on an average, for a period of time that is a significant fraction of the theoretical residence time. The latter is defined as:

\section{Volume of the tundish \\ $\tau=\overline{\text { Volumetric flow rate of steel into (or out of) the tundish }}$}

With the availability of a significant residence time ( $\sim 10 \mathrm{~min}$ or so for industrial caster tundish), the tundish provides an excellent site for carrying out operations such as inclusion separation and flotation, temperature and superheat control, alloy trimming, and so on. However, the efficiency of such processing operations, often being controlled by the rate of the associated heat or mass transport processes, is intricately related to the precise nature of steel flow within the tundish. Consequently, a detailed knowledge of the molten steel's flow parameters (viz., spatial distribution of velocity components, turbulence kinetic energy and so on) in a tundish is a pre-requisite towards any effective process analysis and/or optimisation. As is well known, high temperatures together with the visual opacity of liquid steel and the relatively large size of industrial tundishes, make these molten steel processing units rather cumbersome for
Table 1. Physical properties of water at $20^{\circ} \mathrm{C}$ and steel at $1600^{\circ} \mathrm{C}$ (reproduced from Ref. 10)).

\begin{tabular}{lll}
\hline \multicolumn{1}{c}{ Property } & $\begin{array}{l}\text { Water } \\
\left(20^{\circ} \mathrm{C}\right)\end{array}$ & \multicolumn{1}{c}{$\begin{array}{c}\text { Steel } \\
\left(1600^{\circ} \mathrm{C}\right)\end{array}$} \\
\hline Molecular viscosity $(\mu), \mathrm{kg} /(\mathrm{m} \cdot \mathrm{s})$ & 0.001 & 0.0064 \\
Density $(\rho), \mathrm{kg} / \mathrm{m}^{3}$ & 1000 & 7014 \\
Kinematic viscosity $(\nu=\mu / \rho), \mathrm{m}^{2} / \mathrm{s}$ & $10^{-6}$ & $0.913 \times 10^{-6}$ \\
Surface tension $(\sigma), \mathrm{N} / \mathrm{m}$ & 0.073 & 1.6 \\
\hline
\end{tabular}

direct experimental measurements and virtually impossible for visual observations. As an alternative therefore, reduced scale transparent models using water as the simulating fluid, have often been used to investigate the hydrodynamics and associated transport processes within a continuous casting tundish. As shown in Table 1, water (at $20^{\circ} \mathrm{C}$ ) and molten steel (at $1600^{\circ} \mathrm{C}$ ) have practically equivalent kinematic viscosities, making reduced scale aqueous models an excellent tool for investigating various transport phenomena (such as flow, mixing, alloy trajectories, solid-liquid mass transfer, etc.) in steelmaking reactors (e.g., furnaces, ladles, torpedo cars, tundishes and the like).

Thus, many physical modelling studies ${ }^{10-32)}$ have been reported over the last two decades on widely varying aspects of molten steel processing in tundishes. In the subsequent sections, these are discussed under three main sub-headings, namely, (a) Similarity Considerations and Modelling Criteria, (b) Metallurgical Performance of the Continuous Casting Tundish, and finally, (c) Innovative Technology and Design.

\section{(a) Similarity Considerations and Modelling Criteria}

In reduced scale model studies of isothermal, nonreacting systems, two states of similarities viz., geometrical and dynamic, are required to be satisfied between the model and the full scale. Geometric similarity necessitates that every dimension in the model bears a fixed ratio to the corresponding dimension in the full 
scale. Dynamic similarity (in the present situation, this is synonymous with kinematic similarity) is concerned with the various forces acting on a fluid element and requires that the ratios of the corresponding forces be identical between model and full scale systems.

In any flow system (viz., oxygen furnace, ladle, tundish, etc.) the balances among the various forces acting on a fluid element can be described via the Navier-Stokes equations. For single phase, three dimensional flows in metallurgical tundishes operating under steady state, isothermal, laminar flow conditions, the momentum balance on an elementary volume of liquid steel can be expressed in compact tensorial notation as ${ }^{20.29)}$ :

$$
\frac{\partial}{\partial x_{j}}\left(\rho u_{i} u_{j}\right)=-\frac{\partial p}{\partial x_{i}}+\frac{\partial}{\partial x_{j}}\left(\mu \frac{\partial u_{i}}{\partial x_{j}}\right)+\rho g_{i}
$$

In corresponding dimensionless form, Eq. (2) can also be represented as ${ }^{20,29)}$.

$$
N_{\mathrm{Eu}}=f\left(N_{\mathrm{Re}}, N_{\mathrm{Fr}}\right)
$$

Equation (3), which is the key to dynamic similarity between two geometrically similar systems, can be exactly satisfied between the model and the full scale tundish systems provided the geometric scale factor, $\lambda(=$ $\left.L_{\text {mod }} / L_{\mathrm{f} . s}\right)$ is unity. This essentially means that the dimensions of the model and the full scale systems must be identical. However, in reduced scale modelling studies (viz., $\lambda<1.0$ ), employing water as the simulating fluid, it is impossible to respect equality of both the Reynolds and Froude similarity requirements simultaneously. ${ }^{20,29)}$ This is so, as the kinematic viscosity of water and molten steel are practically identical (viz., Table 1). As a consequence of this, the influence of one of the two numbers (viz., Reynolds or Froude) on the melt flow has to be ignored. Often, in turbulent metal processing operations such as those in tundishes, the transfer of momentum via molecular viscous forces has been regarded to be of only secondary importance. ${ }^{10,12,13,17,19,21-23,29,31 \text { ) }}$ These studies appear to indicate that flows in continuous casting tundishes are Froude dominated and are therefore governed primarily by the inertial and gravitational forces acting on the flowing liquid.

The expression for the momentum balance, equivalent to Eq. (2), for turbulent flow conditions can be represented as ${ }^{20)}$.

$$
\frac{\partial}{\partial x_{j}}\left(\rho u_{i} u_{j}\right)=-\frac{\partial p}{\partial x_{i}}+\frac{\partial}{\partial x_{j}}\left(\mu_{\text {eff }} \frac{\partial u_{i}}{\partial x_{j}}\right)+\rho g_{i}
$$

The corresponding dimensionless form is:

$$
N_{\mathrm{Eu}}=f\left(N_{\mathrm{Re}, \mathrm{t}}, N_{\mathrm{Fr}}\right)
$$

in which, $N_{\mathrm{Re}, \mathrm{t}}$ is the turbulent Reynolds number. ${ }^{20)}$ This represents the ratio of the inertial to turbulent viscous forces $\left(=\rho U L_{\mathrm{c}} / \mu_{\mathrm{eff}}\right)$. The computational work of Sahai and Burval ${ }^{20)}$ and the experimental work of Singh and Koria, ${ }^{22,23)}$ appear to indicate that under turbulent flow conditions, the magnitude of turbulent Reynolds number, $N_{\mathrm{Re}, \mathrm{t}}$, in different tundishes, irrespective to their geometry and dimensions, are expected to be very similar. On the basis of such, the essential conditions for dynamic similarity between model and full scale tundish systems operational under turbulent flow regime, can be expressed as:

$$
N_{\mathrm{Fr}, \bmod }=N_{\mathrm{Fr}, \mathrm{f} . \mathrm{s}}
$$

It is therefore apparent from the discussion presented above, that dynamic similarity between a model tundish (in which flow is assumed to be turbulent (see also later)) and its full scale equivalent can be reasonably respected by maintaining Froude number equivalence between the two. The Froude similarity between model and full scale tundish systems necessitates that the inflow rate of water in the model be related to the inflow rate of molten steel in full scale system according to $10,12,13,17,19,21-23,29,31)$ :

$$
Q_{\mathrm{mod}}=Q_{\mathrm{f} . \mathrm{s}} \lambda^{5 / 2}
$$

Indeed, in many physical modelling studies carried out to-date, a Froude based criterion has been applied to maintain dynamic similarity between two geometrically similar but differently sized (i.e., the model and full scale) tundish systems. This is shown in Table 2, in which the characteristics of many physical model studies reported in the literature have been summarised. There, as seen, numerous experimental investigations were carried out in tundishes having widely varying dimensions and scales, adopting a Froude criterion wherein water flow rates, scaled down in accordance with Eq. (7), were applied. In one investigation however, ${ }^{15)}$ a combined Weber + Froude modelling criterion was applied, embodying a geometric scale factor of 0.6 . In single phase flow modelling investigation, it is rather well known that maintaining Weber number similarity is not at all important (see for example, Eqs. (2) and (4), which do not incorporate any dependence of flow on surface tension forces). In a relatively few studies, ${ }^{10-11)}$ full scale aqueous models were also used, as these could respect both Froude and Reynolds similarities simultaneously. Towards this, it is to be mentioned that Nakajima and coworkers, ${ }^{11}$ based on their extensive experimental trials, have demonstrated that a full scale $(\lambda=1.0)$ water model produces results practically equivalent to those derived from a reduced scale $(\lambda=0.19)$ water model of an industrial tundish. Their observations, as illustrated in Fig. 3, shows that the measured ratios of floating to entraining hollow glass spheres (simulating buoyant non-metallic inclusions in steel), in the full scale and reduced scale water model tundishes can be correlated effectively via the geometric scale factor, $\lambda$. As a consequence of such results, it is to be expected that a model tundish, scaled down on the basis of geometric and dynamic similarities (based on Froude similarity) is likely to simulate flow phenomena of the corresponding full scale system fairly accurately. More evidence on the correspondence between a model and full scale tundish is presented ${ }^{14)}$ in Fig. 4, in which respective dimensionless RTD curves are directly compared. Such evidence within the open literature demonstrates that Froude based modelling criterion is entirely appropriate for isothermal flow simulations of continuous casting tundish systems.

Despite such ${ }^{1,14)}$ and similar ${ }^{10,12,13,17,19,21-23,29,31)}$ 
ISIJ International, Vol. 39 (1999), No. 6

Table 2. Details of the various physical modelling investigations reported in the literature.

\begin{tabular}{|c|c|c|c|c|c|c|c|c|}
\hline \multirow{2}{*}{$\begin{array}{l}\text { Sl. } \\
\text { no }\end{array}$} & \multirow[t]{2}{*}{ Investigators } & \multicolumn{4}{|c|}{ Characteristics of model tundish } & \multirow{2}{*}{$\begin{array}{l}\text { Similarity } \\
\text { criteria }\end{array}$} & \multicolumn{2}{|c|}{ Measurement techniques } \\
\hline & & $\begin{array}{l}\text { Dimensions } \\
(\mathrm{L} \times \mathbf{W} \times \mathrm{H}), \mathrm{m}\end{array}$ & $\begin{array}{l}\text { No. of } \\
\text { strand }\end{array}$ & $\begin{array}{l}\text { Scale } \\
\text { factor }\end{array}$ & Shape of tundish & & RTD & Others \\
\hline 1 & $\begin{array}{l}\text { Govindarajan et } \\
\text { al. }^{15}\end{array}$ & $\begin{array}{l}3.415 \times 0.387 x \\
0.288\end{array}$ & $\operatorname{six}$ & 0.6 & $\begin{array}{l}\text { Rectangular with } \\
\text { sloping wall }\end{array}$ & $\begin{array}{l}\text { Froude }+ \\
\text { Weber }\end{array}$ & -...-..- & -------...- \\
\hline 2 & Collur et al..$^{32}$ & $\begin{array}{l}2.25 \times 0.86 \times 0.40 \\
\text { variable height }\end{array}$ & one & 1.0 & $\begin{array}{l}\text { Rectangular with } \\
\text { sloping wall; curved } \\
\text { bottom }\end{array}$ & $\begin{array}{l}\text { Froude + } \\
\text { Reynoids }\end{array}$ & $\begin{array}{l}\text { Spectropho- } \\
\text { tometry }\end{array}$ & $\begin{array}{l}\text { Floatation of inc- } \\
\text { lusion:COULTER } \\
\text { Multisizer Ile }\end{array}$ \\
\hline 3 & $\begin{array}{l}\text { Sahai and } \\
\text { Ahuja } a^{13}\end{array}$ & $1.32 \times 0.305 \times 0.27$ & Two & 0.33 & $\begin{array}{l}\text { Rectangular with } \\
\text { sloping wall }\end{array}$ & Froude & $\begin{array}{l}\text { Spetropho- } \\
\text { tometry }\end{array}$ & -...-..-.. \\
\hline 4 & $\begin{array}{l}\text { Singh and } \\
\text { Koria }\end{array}$ & $\begin{array}{l}1.0 \times 0.310 \times 0.37 \\
\text { variable width } \\
\text { and height }\end{array}$ & one & 0.28 & $\begin{array}{l}\text { Rectangular with and } \\
\text { without sloping wall }\end{array}$ & Froude & $\begin{array}{l}\text { Conducti-- } \\
\text { metry }\end{array}$ & $\begin{array}{l}\text { Flow pattem: Dye } \\
\text { movement via video } \\
\text { recording. }\end{array}$ \\
\hline 5 & Xintian et al. ${ }^{19}$ & $\begin{array}{l}0.815 \times 0.235 \mathrm{x} \\
0.300(\mathrm{~L} \text { and } \mathrm{W} \\
\text { at the vessel } \\
\text { base) }\end{array}$ & one & 0.33 & $\begin{array}{l}\text { Rectangular with } \\
\text { sloping wall }\end{array}$ & Froude & $\begin{array}{l}\text { Conducti- } \\
\text { metry }\end{array}$ & $\begin{array}{l}\text { Filtration of steel in an } \\
\text { actual caster tundish. }\end{array}$ \\
\hline 6 & Kemeny et al ${ }^{10}$ & $\begin{array}{l}6.768 \times 0.654 \mathrm{x} \\
0.750\end{array}$ & two & 1.0 & $\begin{array}{l}\text { Rectangular with } \\
\text { slopping wall }\end{array}$ & $\begin{array}{l}\text { Reynolds }+ \\
\text { Froude }\end{array}$ & $\begin{array}{l}\text { Spectrophot } \\
\text { ometry }\end{array}$ & $\begin{array}{l}\text { Flow pattern: Through } \\
\text { movement of dye }\end{array}$ \\
\hline 7 & Godiwala et al. ${ }^{36}$ & $01.50 \times 0.20 \times 0.30$ & $\begin{array}{l}\text { Two, } \\
\text { three and } \\
\text { four }\end{array}$ & ---- & $\begin{array}{l}\text { Rectangular with } \\
\text { slopping wall }\end{array}$ & -.--- & -..--.- & (-........ \\
\hline 8 & Nakajima et al. ${ }^{11}$ & $\begin{array}{l}4.14 \times 0.85 \times 0.75 \\
\& \\
0.78 \times 0.167 \times 0.14\end{array}$ & two & $\begin{array}{l}1 \text { and } \\
0.19\end{array}$ & $\begin{array}{l}\text { Rectangular with } \\
\text { slopping side walls }\end{array}$ & $\begin{array}{l}\text { Reynold + } \\
\text { Froude \& }\end{array}$ & 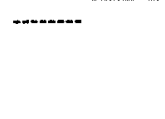 & $\begin{array}{l}\text { Floatation of inclusion } \\
\text { through on line ESZ } \\
\text { method }\end{array}$ \\
\hline 9 & Martinez et al. ${ }^{14}$ & $1.32 \times 0.3 \times 0.28$ & Two & 0.33 & $\begin{array}{l}\text { Rectangular with } \\
\text { slopping wall }\end{array}$ & Froude & Colorimetry & $\begin{array}{l}\text { Floatation of inclusion } \\
\text { via weighing method }\end{array}$ \\
\hline 10 & Chiang ${ }^{17}$ & $\begin{array}{l}2.082(\mathrm{~L}) \& \\
0.4699(\mathrm{H}) ; \mathrm{W} \\
\text { not mentioned }\end{array}$ & one & 0.5 & $\begin{array}{l}\text { Rectangular cross } \\
\text { section with slopping } \\
\text { wall }\end{array}$ & Froude & Colorimetry & ----- \\
\hline 11 & $\begin{array}{l}\text { Mazumdar et } \\
\text { al. }{ }^{29,31}\end{array}$ & $\begin{array}{l}1.2(\mathrm{~L}) \times 0.14(\mathrm{H}) \\
1.76(\mathrm{~L}) \times 0.24(\mathrm{H}) \\
\text { width not } \\
\text { mentioned }\end{array}$ & $\begin{array}{l}\text { two, five } \\
\text { and six }\end{array}$ & $\begin{array}{l}0.15 \\
0.33\end{array}$ & $\begin{array}{l}\text { Rectangular with } \\
\text { inclined wall, skewed } \\
\text { delta shaped }\end{array}$ & Froude & $\begin{array}{l}\text { Conducti- } \\
\text { metry }\end{array}$ & $\begin{array}{l}\text { Flow pattem through } \\
\text { movement of dye }\end{array}$ \\
\hline
\end{tabular}

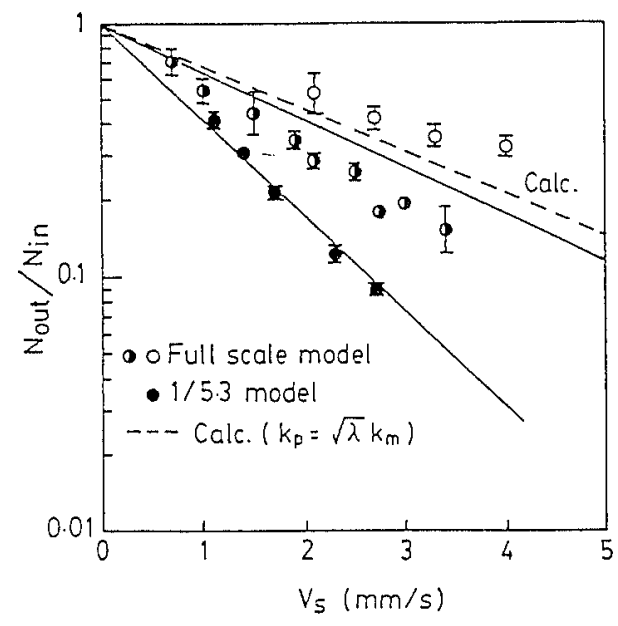

Fig. 3. Separation ratio of hollow glass spheres as a function of Stokes velocity in two different size aqueous models $(\lambda=1.0$ and 0.19$)$ of a two strand slab caster tundish. ${ }^{11)}$

evidence in the literature, the relevance of Froude based modelling to investigate melt flow in tundishes has been called into question by Sahai and Burval ${ }^{20}$ ) in one of

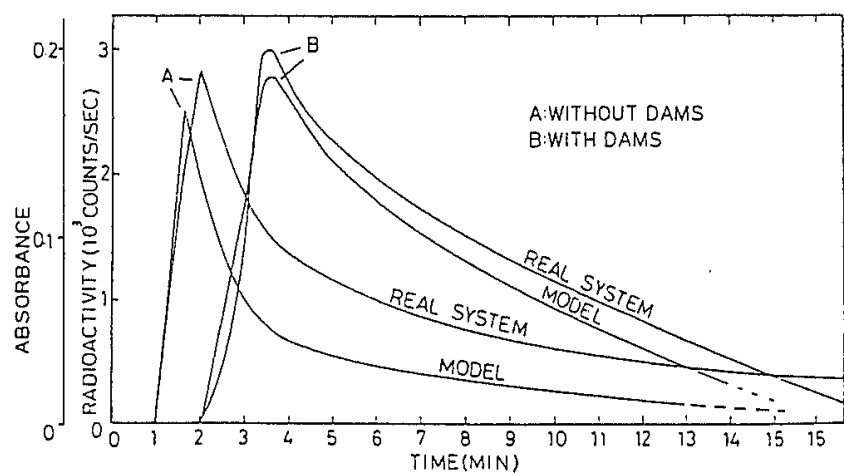

Fig. 4. Experimentally measured Residence Time Distributions (C curves) in reduced (aqueous) and full scale (high temperature) tundish systems with and without flow modifiers. ${ }^{14)}$

their recent publications. The authors, ${ }^{20}$ based on their experimental and computational results, argued that in the isothermal water modelling of flow in a tundish (which has been generally considered to be turbulent ${ }^{20,21)}$, only geometric similarity needs to be maintained, since the model can be operated at any flow rate. 
However, the depth of liquid within the model tundish must correspond geometrically to that in the full scale system for it to be a faithful representation of the other. This equilibrium depth of liquid in a given tundish, as the principle of volume conservation shows, results from a balance between the inflow and the outflow rates, and is therefore uniquely related to the liquid inflow rate. Based on such arguments, it is difficult to understand how a model tundish can be operated at any flow rate, and yet be geometrically similar to its full scale counter part!

In a later study, Mazumdar and coworkers ${ }^{19}$ therefore addressed the issue of similarity in physical model studies of tundish systems, and demonstrated that the depth of liquid in the model and full scale tundishes will only correspond such that complete geometrical similarity between the two is maintained (viz., $H_{\bmod } / H_{\mathrm{f} . \mathrm{s}}=L_{\mathrm{mod}} /$ $L_{\mathrm{f} . \mathrm{s}}=\cdots=\lambda$ ), provided the Froude modelling criterion is applied e.g., the model is operated at a flow rate scaled down in accordance with Eq. (7). In summary, the work of Nakajima and coworkers, ${ }^{11)}$ Martinez et al. ${ }^{14)}$ as well as those of numerous other investigators summarised in Table 2, indicate that reduced scale model studies embodying the Froude modelling criterion is a reasonably effective approach for simulating isothermal flow phenomena in continuous casting tundish systems.

The issue of maintaining dynamic similarity in tundish systems under non-isothermal conditions was also recently addressed by Damle and Sahai ${ }^{30)}$ from an experimental stand point. Through a dimensional analysis of the governing fluid flow and thermal energy transport equations, these authors demonstrated that flow and thermal similarity (assuming that boundary conditions applicable to the model and the full scale systems are also identical in their corresponding non-dimensional form) under non-isothermal conditions, are governed by three dimensionless numbers ${ }^{30)}$ i.e., $\rho U L_{\mathrm{c}} / \mu_{\mathrm{eff}}, \beta T_{\mathrm{o}} L_{\mathrm{c}} g /$ $U_{\text {in }}^{2}$ and $k_{\text {eff }} / \rho_{\text {eff }} C_{\mathrm{p}} U_{\text {in }} L_{\mathrm{c}}$. It was argued that under turbulent flow conditions, the magnitude of turbulent Reynolds number $\left(=\rho U L_{\mathrm{c}} / \mu_{\mathrm{eff}}\right)$ and turbulent Prandtl numbers $\left(=k_{\text {eff }} / \mu_{\text {eff }} C_{\mathrm{p}}\right)$ are expected to be very similar in different tundish systems. Consequently, maintaining $\beta T_{\mathrm{o}} L_{\mathrm{c}} g / U_{\mathrm{in}}^{2}$, identical between the model and the full scale systems, dynamic similarity between the two can be achieved under non-isothermal conditions. These assertions were evaluated by the authors ${ }^{30)}$ against their experimental results derived from non-isothermal, reduced scale models, and reasonably good agreement between theory and experiment was demonstrated. It is useful to mention here that the dimensionless number, $\beta T_{\mathrm{o}} L_{\mathrm{c}} g /$ $U_{\mathrm{in}}^{2}$, represents the ratio of the thermal buoyancy to inertial forces and is therefore, fundamentally, similar to the Froude number, defined earlier, for isothermal flows.

\section{(b) Metallurgical Performance of the Continuous Casting Tundish Systems}

As pointed out previously, present day continuous caster tundishes have a number of roles to play. The most important are ${ }^{25)}$ :

(i) conduit for liquid steel from the ladle to the strands, (ii) to act as a reservoir of steel during ladle changes so that casting can continue, and

(iii) to float out non-metallic inclusions.

The use of the tundish to float out and separate inclusions from the steel melt has been the subject of considerable interest. Accordingly, many physical and mathematical modelling studies are reported in the literature. Although inclusion float out in real continuous casting tundishes cannot be accurately determined from such studies (owing to the large differences between model and full scale systems and the complex physicochemical reactions involved in practice), useful, qualitative information, critical to tundish performance, can nevertheless be deduced from such physical and mathematical model studies.

To quantify the metallurgical process performance i.e., the ability of a given tundish design to float-out and separate non-metallic inclusions, two different experimental approaches have been commonly applied by researchers. These include:

(i) the measurement of residence time distributions (RTD), and

(ii) the direct measurement of inclusion separation through aqueous simulation.

The residence time of fluid within a reactor is defined as the time a single fluid element spends in the reactor vessel. Usually, flow in any tundish is accompanied by a distribution of residence times for different fluid elements (i.e., some fluid elements stay longer, while others spend shorter times within the tundish with respect to the theoretical or nominal residence time). As such, one normally referes to a mean residence time since only plug flow reactors exhibit one unique residence time. As presented in Table 2, RTD characteristics have been measured experimentally in numerous investigations using a variety of on-line measurement techniques. These include, colorimetry, conductimetry and spectrophotometry. Typically, an appropriate (finite or continuous) tracer is injected into the liquid passing through the ladle shroud at time, $t=0$. The concentration of the added tracer is monitored dynamically at the exit nozzle of the tundish via one of the above mentioned techniques. From such measurements, the variation in exit concentrations as a function of time can be obtained. Typical concentrations $v S$. time plots, ${ }^{21)}$ commonly known as the C curve, ${ }^{33)}$ is shown schematically in Fig. 5. In almost all the studies reported to-date, $\mathrm{C}$ curves have been represented in non dimensional form, in which, the concentration has been normalised on the basis of an uniform, well mixed concentration value, while corresponding residence times are normalised with respect to the nominal holding, or theoretical, residence time (e.g., Eq. (1)).

With regards to the shape of the $\mathrm{C}$ curves in tundish systems, these are either associated with one or two peaks, depending on the dimensionless width of a given tundish $(=W / L) .{ }^{21)}$ As shown in Fig. 5, narrow tundishes are likely to exhibit two peaks as opposed to one peak in wider tundishes, these being closely related to the nature of fluid motion in the tundishes. Apart from these, the general nature of the RTD curves (viz., characterised by 


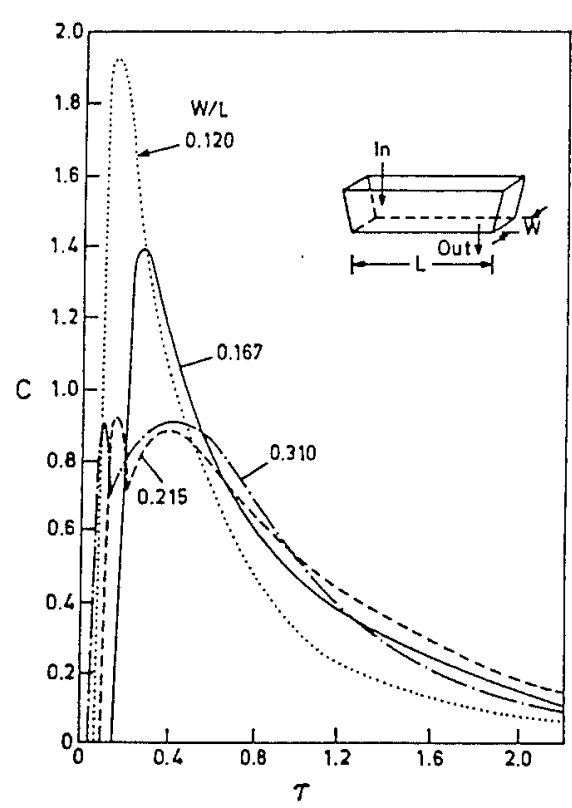

Fig. 5. Experimentally measured $C$ curves in a water model of a single strand slab casting tundish systems at various values of the dimensionless tundish width. $^{21)}$

a "minimum break through time" followed by a rapid increase in concentration and subsequent near exponential decay) were found to be very similar for a wide variety of experimental conditions. Thus, parameters such as, slag cover, ladle shroud to tundish nozzle distance and their symmetric and asymmetric locations, inclined or perpendicular walls, flow rate control mechanisms (nozzle or stopper rod), bath height and submergence depth of the ladle shroud, were found to have practically no influence on the shape of the RTD curves. ${ }^{21)}$

From a typical Residence Time Distribution curve, such as those shown in Fig. 5, important RTD parameters such as the minimum break through time $\left(t_{\min }\right.$ or $\theta_{\min }$, in corresponding dimensionless form), the time to attain peak concentration $\left(t_{\text {peak }}\right.$ or $\left.\theta_{\text {peak }}\right)$ and the average residence time $\left(t_{\mathrm{av}}\right.$ or $\left.\theta_{\mathrm{av}}\right)$, can be readily estimated and incorporated in an appropriate flow model to estimate the proportions of dead $\left(V_{\mathrm{dv}}\right)$, plug $\left(V_{\mathrm{pv}}\right)$ or dispersed plug $\left(V_{\mathrm{dpv}}\right)$ and well mixed $\left(V_{\mathrm{mv}}\right)$ volumes in a given tundish. On the basis of such estimates, inferences on the chemical efficiencies of various transport controlled processes (viz., inclusion separation, thermal mixing, etc.) in a given tundish can be made.

In a much earlier work, Kemeny et al. ${ }^{10)}$ applied a mixed model to analyze their experimental Residence Time Distributions data. In this, the various fractional volumes are correlated with the RTD parameters $a^{10)}$ :

$$
\begin{gathered}
V_{\mathrm{dv}}=1 .-\theta_{\mathrm{av}} \\
V_{\mathrm{pv}}=\theta_{\min }=\theta_{\text {peak }} \\
V_{\mathrm{mv}}=\frac{1}{C_{\text {peak }}} .
\end{gathered}
$$

As an additional requirement, the three volume fractions calculated on the basis of the above, should also add up to unity, viz.,

$$
V_{\mathrm{dv}}+V_{\mathrm{pv}}+V_{\mathrm{mv}}=1
$$

In a subsequent study, Ahuja and Sahai, ${ }^{13)}$ on the basis of their experimental observations, questioned the adequacy of the mixed flow model and suggested that a mixed model is not truly applicable to tundish systems since,

(i) considerable axial, or longitudinal, diffusion is present in tundish systems. Given such, the minimum break through time and the time, at which peak concentration is reached, are not equal e.g., $\theta_{\text {min }} \neq \theta_{\text {peak }}$, and

(ii) the three volume fractions calculated using Eqs. (8) through (10) do not add up to unity as required by Eq. (11).

To avoid such shortcomings associated with the mixed flow model, a "modified mixed model" was proposed for the tundish system by Ahuja and Sahai. ${ }^{13)}$ According to this, the tundish volume is divided into three parts, namely a dead volume $\left(V_{\mathrm{dv}}\right)$, a dispersed plug volume $\left(V_{\mathrm{dpv}}\right.$ ) (in contrast to a plug volume in the mixed flow model) and a well mixed volume $\left(V_{\mathrm{mv}}\right)$. These fractional volumes are then calculated from the $C$ curves as:

$$
\begin{gathered}
V_{\mathrm{dv}}=1 .-\theta_{\mathrm{av}} \ldots . . \\
V_{\mathrm{dpv}}=\frac{\left(\theta_{\mathrm{min}}+\theta_{\mathrm{peak}}\right)}{2} \\
V_{\mathrm{mv}}=1 .-V_{\mathrm{dv}}-V_{\mathrm{dpv}}
\end{gathered}
$$

In several subsequent studies, the modified mixed model was used by many researchers ${ }^{28,31)}$ to characterize melt flow in continuous casting tundish systems. Schematics of the mixed and modified mixed flow models together with their associated theoretical " $C$ " curves, reproduced from Ref. 13), are shown respectively in Figs. 6(a) and 6(b).

The calculation of dead volume, $V_{\mathrm{dv}}$, (arbitrarily defined as that volume of fluid which spends more than two times the theoretical residence time $(2 \tau)$ in the tundish) from the experimental $\mathrm{C}$ curve, which is key to the estimation of the various volume fractions in a tundish, has been reviewed at length in a recent article by Sahai and Emi. ${ }^{34)}$ Their work shows that Eqs. (8) or (12) (viz., $V_{\mathrm{dv}}=1-\theta_{\mathrm{av}}$ in which, $\theta_{\mathrm{av}}$ equals to the measured mean time up to $\theta=2$ divided by the theoretical residence time) is applicable to tundishes in which the dead volume is essentially stagnant. However, "dead" regions in tundish, are typically not stagnant, but rather slowly moving. For such situations, Sahai and Emi went on to show that the correct expression for the estimation of fractional dead volume (that is slowly moving) is ${ }^{34)}$ :

$$
V_{\mathrm{dv}}=1-\frac{Q_{\mathrm{a}}}{Q} \theta_{\mathrm{av}}
$$

In Eq. (15), $Q_{\mathrm{a}} / Q$ is the fractional volumetric flow rate through the active region and is numerically equal to the area under the $C$ curve between the bounds $\theta=0$ to $\theta=2$. It is instructive to note here that if the ratio $Q_{\mathrm{a}} / Q$ in Eq. (15) is unity, Eqs. (12) and (15) then become analogous, provided the dead region in a tundish is stagnant. Interestingly, as pointed out by Sahai and Emi, and also 

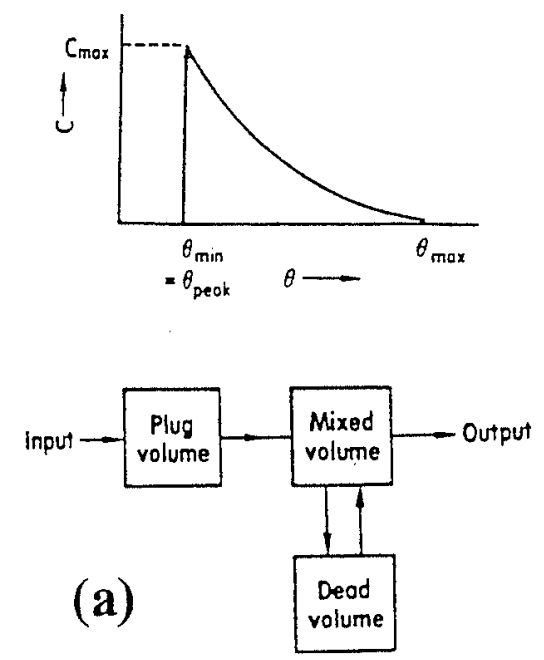

Fig. 6. Schematics of the flow models and their associated theoretical $C$ curves ${ }^{13)}$ (a) mixed flow model and (b) modified mixed fiow model.

noted by the present authors, in none of the studies reported to date, have the dead and the related volume fractions, been estimated correctly. Examination of numerous estimated RTD data in the literature indicates that practically in all the studies reported to date on RTD in tundishes, the fraction, $Q_{\mathrm{a}} / Q$ in Eq. (15), has been assumed to have a value of unity. In reality, the ratio, $Q$ a $/ Q$ can have a value much lower than unity and this is likely to induce significant error in the calculation of the dead and the associated volume fractions, as has been demonstrated by Sahai and Emi.

Inclusions in tundishes generally have their source in the carry over slag from the ladle (in the form of micro-droplets), in the entrainment of tundish slag, the erosion of the refractory walls, chemical/steel deoxidation reactions, etc. As the population of inclusions, their chemistry and size distributions exert profound influences on the finished steel product, consequently, the removal or separation of non-metallic inclusions in tundishes has been the subject matter of a large number of physical modelling investigations. ${ }^{13,23,29,31)}$ These studies $^{13,23,29,31)}$ have accordingly helped identify specific RTD characteristics of tundish systems that are directly related to the efficiency of inclusion separation and float out. For example, Ahuja and Sahai have postulated that to achieve maximum inclusion separation ratio in a given continuous casting tundish, it is necessary to ensure ${ }^{13)}$ :

(i) minimum spread of residence times,

(ii) minimum dead volume,

(iii) large ratio of plug to dead volume and relatively large ratio of plug to mixed volume,

(iv) surface directed flow,

(v) quiescent slag layer, and

(vi) contained regions of mixing.

Many studies have shown that the basic tundish design, operating parameters (viz., throughput rate, bath depth, inflow rate etc.), as well as various flow modifiers (such as dams, weirs, slotted baffles, etc.), influence RTD values in tundishes and therefore exert considerable influence on the efficiency of inclusion separation. It is now rather well known that a tundish without any flow modifier do

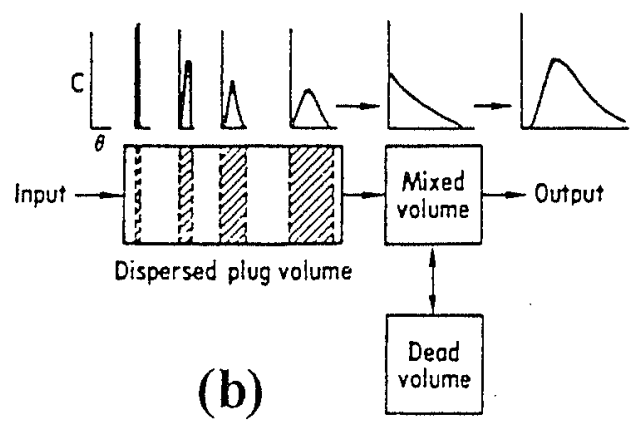

not satisfy many of the requirements pointed out above, essential to inclusion removal and consequently, critical to the production of clean steel. For example, unbaffled tundishes are associated with considerable short circuiting, ${ }^{10,21,31)}$ large dead volumes, ${ }^{13,31)}$ significant turbulence ${ }^{25)}$ and slag droplet entrainment, etc., which are potentially detrimental to the flotation of nonmetallic inclusions. It must however be mentioned that specific conditions for removal of inclusions vary largely from one practice to another, the size of inclusions being a critical factor in determining the effectiveness of a given tundish design to separate and float out inclusions.

Thus, numerous physical modelling studies have been carried out ${ }^{10-14,17-19,21-28,31,32)}$ in widely varying tundish sizes and geometries to primarily investigate the influence of various flow modifiers on the associated Residence Time Distributions. The weir (defined as ${ }^{10}$ ): a partial dam, covering the complete width of the tundish and extending from above the liquid pool surface to a level above the tundish bottom, allowing liquid to flow underneath) can ensure a quiescent slag layer and help contain turbulence, but may not often eliminate short circuiting ${ }^{10,23)}$ completely. On the other hand, the dam (defined as ${ }^{10)}$ : a partial dam covering the complete width of the tundish and extending from the bottom of the tundish to a level below the surface of the liquid allowing liquid to flow over it), can completely eliminate short circuiting, ${ }^{23)}$ create surface directed flow ${ }^{13)}$ (necessary for the capture of inclusion by the overlying slag phase) and has the potential to restrict the turbulence of the ladle stream within the inlet region. As a consequence of these, the flow of liquid in the tundish tends to become uniform. ${ }^{23)}$ The most significant influence of a dam is, however, a marked increase in the average residence time in comparison to an equivalent situation with a weir only. ${ }^{10)}$

The dam and the weir have also been applied in conjunction to produce the desired results in continuous caster tundish systems. Many physical model stu$\operatorname{dies}^{10,11,23,31)}$ clearly indicate that desirable conditions for the separation of non-metallic inclusions in tundishes 
Table 3. Influence of width, bath height and inlet-exit distances on Residence Time Distribution parameters in a single strand water model of a slab casting tundish (reproduced from Ref. 21)).

\begin{tabular}{|c|c|c|c|c|c|c|}
\hline \multirow{2}{*}{$\begin{array}{l}\text { Sl. } \\
\text { No. }\end{array}$} & \multicolumn{3}{|c|}{ Tundish dimension, $\mathrm{mm}$} & \multicolumn{3}{|c|}{$\begin{array}{c}\text { Residence Time Distribution } \\
\text { parameters, } s\end{array}$} \\
\hline & Width & Height & $\begin{array}{l}\text { Inlet-exit } \\
\text { distance }\end{array}$ & $t_{\min }$ & $t_{\mathrm{peak}}$ & $t_{\mathrm{av}}$ \\
\hline 1 & 310 & 180 & 780 & 32 & 209 & 310 \\
\hline 2 & 310 & 260 & 780 & 31 & 262 & 444 \\
\hline 3 & 310 & 340 & 780 & 35 & 253 & 618 \\
\hline 4 & 310 & 260 & 680 & 23 & 234 & 419 \\
\hline 5 & 310 & 260 & 880 & 43 & 256 & 457 \\
\hline 6 & 150 & 180 & 780 & 36 & 72 & 150 \\
\hline 7 & 150 & 260 & 780 & 44 & 78 & 216 \\
\hline 8 & 150 & 340 & 780 & 44 & 101 & 283 \\
\hline 9 & 150 & 260 & 680 & 27 & 78 & 208 \\
\hline 10 & 150 & 260 & 880 & 62 & 103 & 230 \\
\hline $1 \mathrm{I}$ & 120 & 120 & 780 & 21 & 40 & 75 \\
\hline 12 & 120 & 180 & 780 & 25 & 51 & 112 \\
\hline 13 & 120 & 260 & 780 & 30 & 45 & 175 \\
\hline 14 & 72 & 260 & 680 & 8 & 16 & 94 \\
\hline 15 & 72 & 260 & 780 & 12 & 20 & 100 \\
\hline 16 & 72 & 260 & 880 & 24 & 33 & 103 \\
\hline
\end{tabular}

(such as no short circuiting, a contained region of turbulence associated with the inlet flow from the ladle, a large average residence time, etc.) can effectively be created using appropriate designs of dam and weir combinations. ${ }^{12)}$ Similarly, slotted baffles with inclined holes (inclined to the horizontal by $30^{\circ}$ or so, which typically provides upwardly directed fluid from the central pouring region so that the probability of inclusion-slag contact is enhanced) can produce results equivalent, or even superior, to those produced by dam + weir combinations. ${ }^{31)}$ It is however, important to note here that flow modifiers, although vital to the enhancement of tundish performance, are unlikely to produce the desired results under all conditions, since their physical dimensions, design and locations within the tundish, etc. profoundly influence the Residence Time Distributions and therefore, the associated proportions of plug, dispersed plug and mixed flow volumes. ${ }^{10,13,14,17-32)}$ In addition to these, the size of inclusion, as already pointed out, is a key factor and must be taken into account before a precise assessment of the effectiveness of the flow modifiers is made. For instance, if inclusions are less than $30-40 \mu \mathrm{m}$ in size, their Stokes rising velocity are so small (less than $1 \mathrm{~mm} / \mathrm{s}$ ), that the major portion of them will flow with the steel into the exit ports (or SEN's) to the casters, whether or not dams and weirs are present (see also later).

Residence Time Distributions, as one would normally anticipate, depend strongly on the basic geometry and the physical dimensions of the tundish. According to Singh and Koria, ${ }^{21}$ the width of the tundish, the depth of liquid in the tundish, and the distance between the inlet and outlet, influence measured RTD values (viz., $t_{\text {min }}, t_{\text {peak }}$ and $t_{\text {av }}$ ) the most. Therefore, the performance of any given tundish, baffled or unbaffled, is expected to be sensitive to the choice of such operating variables.
This is illustrated in Table $\mathbf{3}$, in which measured residence times in a single strand water model slab caster tundish have been summarised for different values of dimensionless tundish width, dimensionless bath depth and dimensionless inlet-outlet distances. ${ }^{21)}$ As seen, of the three tundish dimensions mentioned above, it is the inlet-outlet distance that most influences the RTD parameters. In addition to the above, the method of pouring (submerged vs. shrouded) in a given tundish design ${ }^{15,28)}$ was also found to have a considerable influence on the Residence Time Distributions. For example, the extent of short circuiting, the level of turbulence within the tundish, the proportions of various fluid volumes, etc., depend considerably on the method of pouring. It was also demonstrated experimentally by Koria and Singh, ${ }^{28)}$ that flow modifiers are likely to influence RTD differently, under different methods of pouring.

The role of gas injection in tundishes in conjunction with flow modifiers have been extensively studied by many investigators. ${ }^{6,13,17,19)}$ Water model, as well as pilot scale, trials have indicated that inert gas bubbling can reduce the extent of dead volumes in tundishes and thus enhance the separation efficiency of inclusions. These studies have also indicated that improved tundish performance depends on appropriate location of gas bubblers, their numbers and the gas flow rates applied. These are by no means unique and must be determined by trial and error, for each individual tundish geometry and baffle configurations.

Based on their own experimental data, as well as those reported in the literature, several empirical relationships were developed by Singh and Koria ${ }^{21,23)}$ to correlate RTD parameters with operating conditions. Their studies $^{21,23)}$ show that while $\theta_{\min }$ and $\theta_{\text {peak }}$ are weakly dependent on a "nozzle Froude number" (proportional to $\mathrm{Fr}^{-0.082}$ and $\mathrm{Fr}^{-0.029}$ respectively), $\theta_{\mathrm{av}}$ is independent of "nozzle Froude number" (defined as: $U_{\text {in }}^{2} / g d_{\text {noz }}$ ). In a separate study, Burval and Sahai ${ }^{20)}$ also reported similar findings and concluded that the average residence time in tundish system is independent of Froude number (undefined $^{20)}$ ). Such observations are difficult to rationalise, since flow phenomena in tundishes are known to be essentially Froude dominated. ${ }^{11,14,29)}$

Meaningful comparisons between the results of various investigations are difficult, since widely varying definitions of Froude number ${ }^{21,29,30)}$ (viz., nozzle Froude number based on the inlet velocity and shroud diameter, $d_{\text {noz }}$ (sometimes referred to as the inlet Froude number ${ }^{13,21)}$ ), the "natural Froude number" based on the depth of liquid, ${ }^{29)} L$, or that based on the hydraulic radius, ${ }^{30)} R_{\mathrm{h}}(=4 \times$ wetted cross section/wetted perimeter of the tundish)) have been applied. It is also instructive to note that Froude numbers based on liquid depth or hydraulic radius as the characteristic length, are not truly independent $\prod$ groupings, since $L$ or $R_{\mathrm{h}}$ cannot be varied at will, without changing the dimensions of the exit nozzle or its opening, to accommodate higher or lower flow rates. As a consequence of such, it is likely to be difficult to quantify experimentally the precise influence of Froude numbers on RTD, based on published data in the 

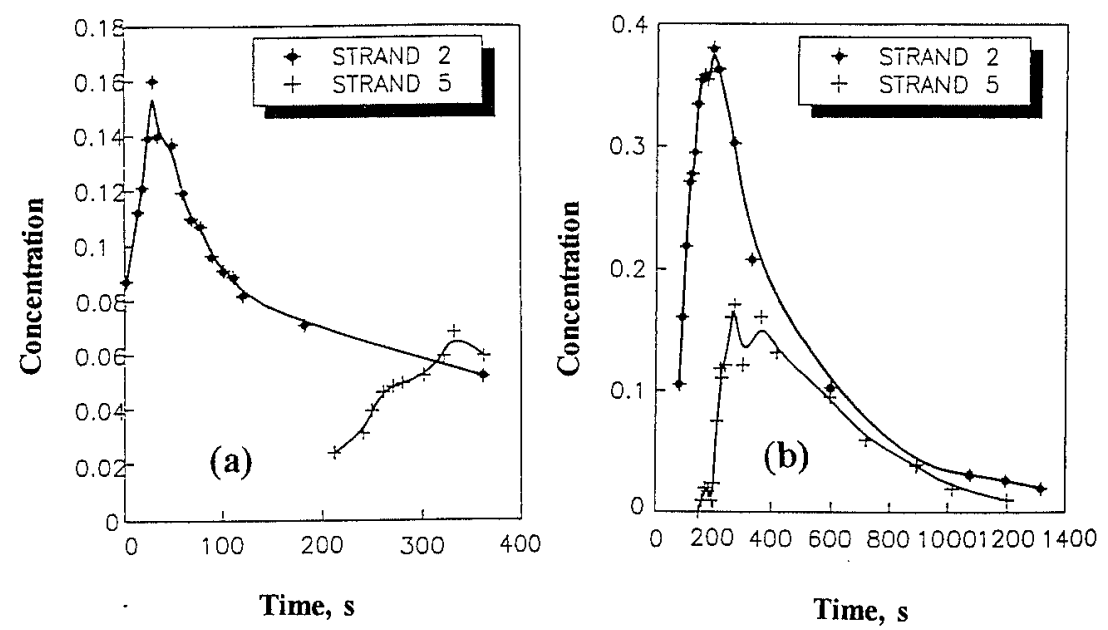

Fig. 7. Concentration $v s$. time plot in a five strand continuous caster tundish illustrating the influence of flow modifiers on the extent of strand dissimilarity ${ }^{18)}$ (a) before the application of flow modifiers and (b) after the application of flow modifiers (strand $\# 2$ closest to the pouring stream and strand $\# 5$ farthest from the pouring stream).

literature. An in-depth analysis of the underlying physical phenomena, coupled with carefully designed experimental work, is called for, to resolve such contradictions.

Within the open literature, other contradictions also exist on the influence of throughput rate on RTD. For example, Collur et al. ${ }^{32)}$ have reported that a noticeable increase in the minimum residence time, $t_{\min }$, coupled with an improved inclusion separation, can be achieved by decreasing the throughput rate in any given tundish. In contrast, Chiang, ${ }^{17)}$ based on his experimental results, suggested quite the opposite. Similarly, while Collur et $a l .{ }^{32)}$ found that the minimum residence time can be increased by increasing the depth of tundish bath, the work of Singh and Koria ${ }^{21)}$ indicates that minimum residence time is inversely proportional to bath depth (for example, $\left.\theta_{\min } \propto(\text { Dimensionless height })^{-0.607}\right)$. In our effort to rationalise such anomalies, it was noted that detailed experimental procedures and conditions are often not reported by investigators. Therefore, it becomes practically impossible to compare the results of one physical model study with those of another.

The many physical model studies reported in the literature and summarised in Table 2, were primarily concerned with single strand and symmetrical two strand tundish systems, typical of slab casting. In contrast to this, multi strand tundishes, both symmetrical and asymmetrical, applied typically to billet casters, have been the subject of fewer investigations. While the requirements for inclusion flotation, etc. in such systems remains essentially the same as those for single strand tundish systems (viz., small dead volume, surface directed flow, contained region of turbulence, etc.), similarity (thermal as well as material) between the strands is an issue of practical concern. This is to be expected, since uniformity of product quality can only be maintained by maintaining strand similarity. To this end, the physical model studies of Martinez and Solis, ${ }^{18)}$ as well as Mazumdar et al. ${ }^{31}{ }^{31}$ have indicated that considerable strand variations is typical of such systems and is influenced strongly by the tundish geometry and the operating conditions. These studies $^{18,31)}$ have further indicated that strand dis- similarity can be reduced and controlled effectively by incorporating appropriate flow modifiers within a given tundish design. This is illustrated in Fig. 7, in which the improvement in strand similarity in a five strand caster tundish, through the placement of appropriately designed set of dams, is readily evident.

In physical model studies of multi-strand tundishes, experimental data on RTD were typically measured and reported for individual strands only. ${ }^{18,26,31)}$ From such measurements (e.g., the $\mathrm{C}$ curves), as one would note here, the proportions of various flow volumes (e.g., dead, plug, well mixed, etc.) cannot be directly estimated, since many of the concepts applied to evaluate $C$ curves for single strand tundish systems, presented earlier, cannot be extrapolated to mult-strand tundish systems in a straight forward fashion. For example, the area under an individual $E(t)$ (for explanation see list of symbols) vs. $t$ curve is not unity and hence Eq. (8) etc. is not applicable. Furthermore, the minimum break-through time, or the time at which peak concentration is reached for the exterior most exit nozzle, may at times, be greater than, or close to, two times the theoretical residence time. As a consequence of these considerations, modified procedures are required for evaluating the set of $C$ curves, and hence performance parameters, for a multi-strand tundish system.

Consider, therefore, a multi strand tundish, having $N$ strands, operating at a constant liquid head, such that the volumetric flow rate $Q$ through the individual strands is identical. The amount of injected tracer flowing out in a time period $\Delta t$ through any of the $N$ strands (say the " $i$ " th strand) is:

$$
\Delta m_{i}=C_{i}(t) Q \Delta t
$$

Similarly, the corresponding fraction of material that flows out through the exit " $i$ " in the same period is represented by:

$$
\frac{\Delta m_{i}}{M}=E_{i}(t) \Delta t
$$

or, in corresponding differential form, 

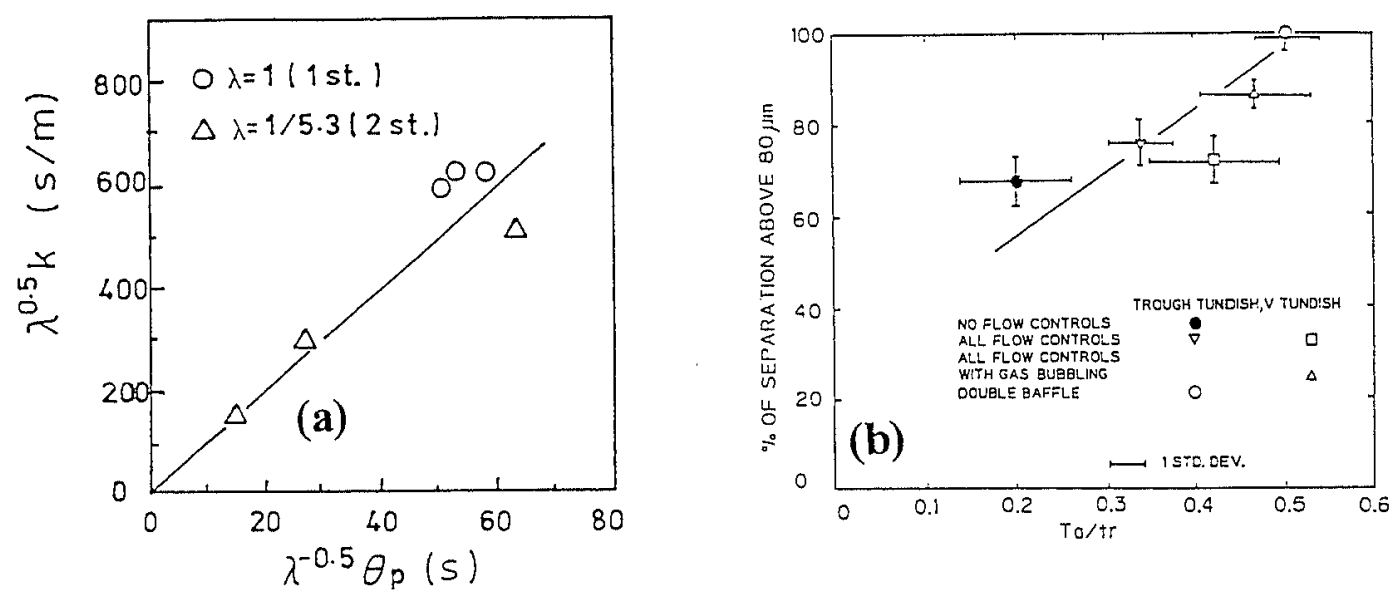

Fig. 8. Inclusion (holow glass micro-spheres) separation and its relationship with Residence Time Distribution parameters (a) the variation of separation rate constant with plug flow volume fraction ${ }^{11}$ ) and (b) variation of percent separation as a function of dimensionless peak residence time. ${ }^{14)}$

$$
\frac{d m_{i}}{M}=E_{i}(t) d t
$$

In these, $M$ is the total mass of the pulse tracer injected and $E_{i}(t)\left(=C_{i}(t) Q / M\right)$, is the Residence Time Distribution Function for the $i$ th strand. Expanding Eq. (18) for $i=1,2 \cdots N$ and integrating the resultant expression between the limit $t=0$ to $t=\infty$, it can be readily shown that:

$$
\int_{0}^{\infty} E_{1}(t) d t+\int_{0}^{\infty} E_{2}(t) d t+\cdots=1.0
$$

or,

$$
\int_{0}^{\infty} E(t) d T=1.0
$$

in which, $E(t)$, the overall Residence Time Distribution Function, is the sum of the individual RTD functions for the $N$ strands. Based on the above discussion, a characteristic RTD curve can be readily derived for a given tundish from the individual strand data. It is to be noted here that the residence time distribution function, $E$ is directly proportional to the concentration, $C$, since $Q$ and $M$ are constants in the tundish system. Therefore, an $E$ vs. $t$ curve can readily be translated, if required, into a $C$ vs. $t$ curve. Various fractional volumes such as, dead, plug, or well mixed volumes, etc. in the tundish can then be estimated following a procedure, essentially identical to those presented earlier (Eqs. (8) through (15)).

Direct measurements on the separation of hydrophillic and hydrophobic buoyant particles in aqueous tundish systems have also been carried out by several investigators ${ }^{11,14,32)}$ to identify the fluid flow conditions essential for floatation of non-metallic inclusions in continuous casting tundish systems. In these studies, hollow glass spheres (simulating non-metallic inclusions in steel melts) were introduced into the tundish in the form of a slurry via the ladle shroud and the exit particle concentration (typically particle number density or particle weight) was monitored via various techniques such as, the aqueous particle sensor (APS II) based on the on-line Electric Sensing Zone (ESZ) ${ }^{11)}$ technique, the COULTER Multisizer II ${ }^{32)}$ (an off-line ESZ technique), conventional weighing, ${ }^{14)}$ and so on. Although, as already mentioned, it is not evident that measured separation ratios from aqueous systems can be scaled up to the full scale system on a one to one basis, never the less, such studies can provide useful insight into the kinetics of inclusion floatation and separation in tundish systems. Indeed, direct experimental measurements of Nakajima et al. ${ }^{11)}$ on two different size water models have confirmed that any increase in the proportion of plug flow volume is likely to lead to an increase in the separation efficiency of inclusions. Similarly, experimental trials of Martinez et al. ${ }^{14)}$ in two different shaped tundishes operated with, and without flow modifiers, have shown that any increase in the value of $t_{\text {peak }}$, the time at which the peak concentration is reached, leads to a noticeable increase in the inclusion $(\sim 80 \mu$ m dia. $)$ separation efficiency. These observations, ${ }^{11,14)}$ illustrated respectively as Figs. 8(a) and 8(b), also appear to indicate that the removal of relatively larger size inclusions from the continuous casting tundish systems can be assessed qualitatively from the corresponding RTD curves. Towards this, it is instructive to note that plant scale trials on industrial tundish systems have also confirmed ${ }^{19)}$ that increased separation efficiency of non-metallic inclusions, such as $\mathrm{Al}_{2} \mathrm{O}_{3}, \mathrm{SiO}_{2}$ etc. ( $\sim 50 \mu$ m dia.) can be achieved by increasing the relative proportions of plug flow volumes, through the placement of appropriately designed flow modifiers (e.g., a dam) in the tundish.

\section{(c) Innovative Technology and Design}

Physical model studies of continuous casting tundish systems have been popular in the past, not only to investigate the hydrodynamic performance of continuous casting tundishes, but also to develop new technology. For example, many modifications and improvements associated with tundish operations in the steel industries (viz., optimum baffle designs, enhancement of casting rates, etc.) have been the result of elaborate laboratory scale water model investigations. ${ }^{14,15,17,18,32)}$ On other 


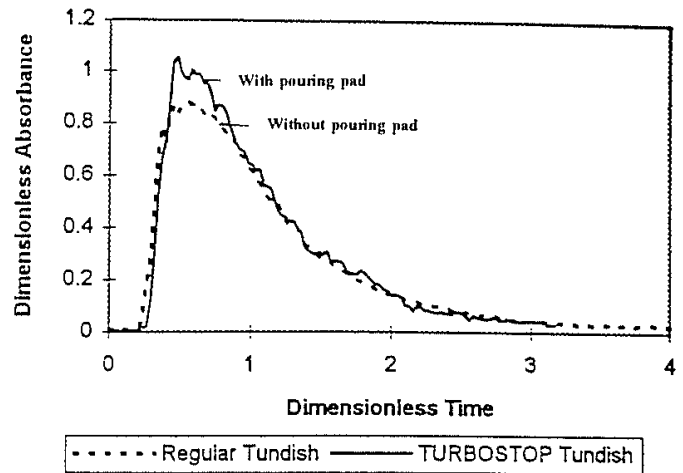

Fig. 9. The influence of using a pouring pad on the magnitude of peak concentration value. ${ }^{27)}$

fronts, water model trials have also been carried out to help develop new and emerging technologies. Most notable among these are appropriate operating designs of turbulence inhibitor pouring pads ${ }^{25,27)}$ (essential for controlling and restraining turbulence in the pouring region), a super tundish design, ${ }^{17)}$ etc., which were arrived at by carefully designed water model investigations.

Turbulence in a tundish, if not properly contained, can be detrimental to the inclusion removal capability of continuous casting tundish systems. ${ }^{25)}$ By reducing the turbulence in the tundish, conditions closer to laminar flow can be achieved, thereby providing a more quiescent bath to allow for enhanced inclusion separation. To inhibit turbulence in tundishes, and to achieve superior tundish performance, various designs of pouring pads have been developed by the steelmaking industry. Figure 9, reproduced from Ref. 27), provides a direct performance comparison of two different tundish configurations in terms of their respective RTDs, operated with, and without, a pouring pad. There, the pouring pad is clearly seen to increase the peak concentration value. This, in turn, is likely to decrease the proportions of well mixed volume in the system, thereby enhancing the inclusion separation efficiency, as has been observed experimentally by Crowley and Lawson. ${ }^{27)}$ Based on the results of such water model trials, appropriate pouring pads for actual caster tundishes have been designed and are currently used in the industry. Industrial findings have reported superior cleanliness of steel through better tundish performance. ${ }^{25,27)}$

In an extensive experimental study, the phenomenon of nozzle blockage in continuous casting tundishes was investigated by Dawson. ${ }^{16)}$ Through carefully designed water model and pilot scale experiments, the author demonstrated that nozzle blockage due to inclusion deposition is the result of a separated flow at the nozzle wall. Furthermore, the origin of such flow separation was found to be related closely to the alignment of the drainage nozzle with the tundish exit port and the wall roughness parameter. It was concluded ${ }^{16)}$ that a marginal misalignment of about 2 to $3^{\circ}$ can initiate separated flow, leading to deposition of solid inclusions on the nozzle wall, leading finally to nozzle blockage.

The formation of funnel vortices in continuous casting tundish is another important aspect of tundish metallurgy, investigated well with the aid of physical modelling. It is rather well known that vortexing often leads to dirty steel by drawing tundish slag into the mould and must therefore be avoided. To achieve desired tundish performance, therefore, specific "vortex killers" for tundishes have been developed. ${ }^{17)}$ Here again, carefully designed water model experiments were used as the basis for arriving at a suitable design for a "vortex killer".

\section{Mathematical Modelling Studies}

The operating conditions (viz., high temperature and visual opacity of molten steel, massive size of industrial tundishes, etc.) prevalent in steel plants, pose serious problems for any direct and elaborate experimental investigation. Consequently, mathematical modelling has been a reasonable alternative to investigate hydrodynamics and the associated heat and mass transfer phenomena in continuous casting tundish systems. To date, extensive mathematical modelling of various aspects of tundish metallurgy viz., hydrodynamics, ${ }^{35-39,41)}$ residence time distributions, ${ }^{40,43)}$ inclusion and thermal energy transport, ${ }^{42,46,47,49,51-57)}$ electromagnetic stirring, ${ }^{44)}$ turbulence phenomena, ${ }^{48,58)}$ etc., have been carried out and reported in the literature. Considerable efforts have been made through these studies to develop a reliable and predictive mathematical framework to investigate transport phenomena of relevance to industrial continuous casting tundish systems. For the convenience of the present discussion, mathematical model studies ${ }^{35-59)}$ have been summarised in this section under three main headings namely, (a) Fluid Flow and Residence Time Distributions, (b) Inclusion Transport and Separation and (c) Thermal Energy Transport.

\section{(a) Fluid Flow and Residence Time Distributions}

In some very early work, Debroy and Sychterz ${ }^{35)}$ carried out a numerical simulation of fluid flow in a two strand, symmetrical, slab casting tundish. Drastic simplifications were applied by the authors ${ }^{35}$ ) and the flow phenomena were modelled via a steady state, two dimensional, turbulent flow model that disregarded any variations of flow variables along the width of the tundish. To assess the adequacy of the 2-D flow modelling to tundish systems, the numerical results of Debroy and Sychterz ${ }^{35)}$ have been compared directly, in Fig. 10, with equivalent predictions ${ }^{41)}$ derived from more elaborate three dimensional models. There, evidently, the 2-D model of Debroy and Schyterz is seen to produce markedly different flow patterns in the central vertical planes of the two strand symmetrical tundish system, in comparison to the three dimensional model results of $\mathrm{He}$ and Sahai. ${ }^{41)}$ For example, entrainment of liquid by the incoming jet of liquid is seen to be entirely absent in Fig. 10(a). The comparison illustrated in Fig. 10, together with many other pieces of evidence available within the literature $^{36,42)}$ (see also later), clearly indicate that flow phenomena in continuous casting tundishes are three dimensional with considerable spatial variations. As a consequence of these, a two dimensional turbulent flow model is not usually adequate for describing flow phenomena in typical tundishes.

Three dimensional, turbulent flow models (steady or 


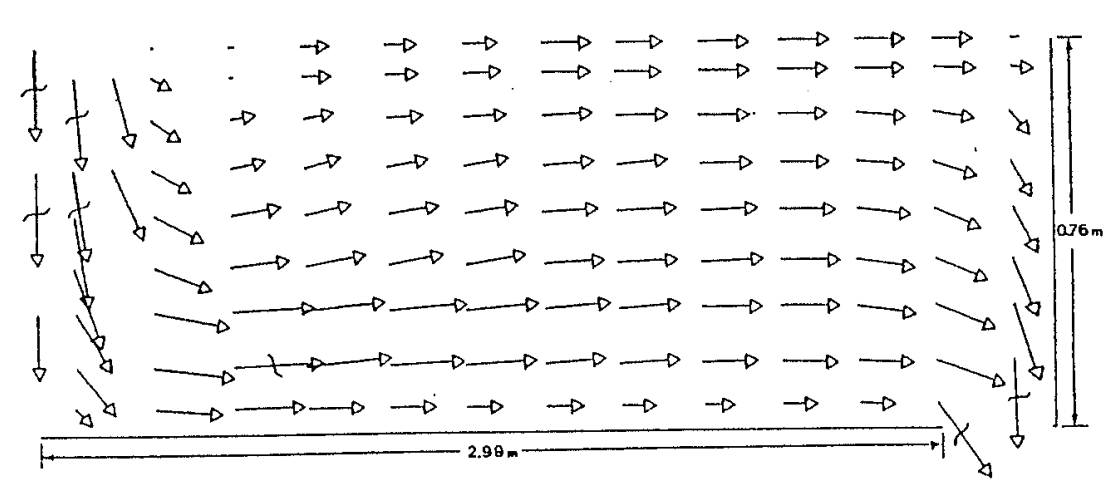

(a)

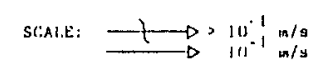

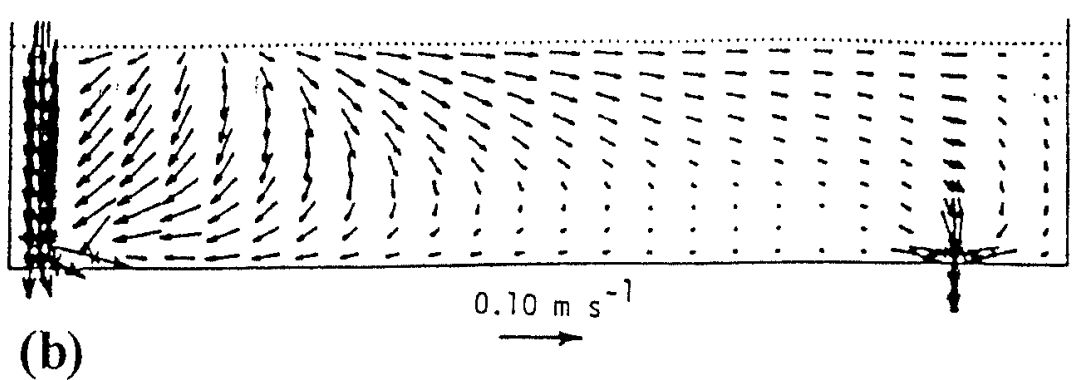

Fig. 10. A comparison of predicted flow patterns in the central vertical plane of two strand symmetrical slab caster tundish systems deduced via (a) the two dimensional (b) the three dimensional turbulent flow models.

(a) after Debroy and Sychterz ${ }^{35)}$ (b) after He and Sahai ${ }^{41)}$

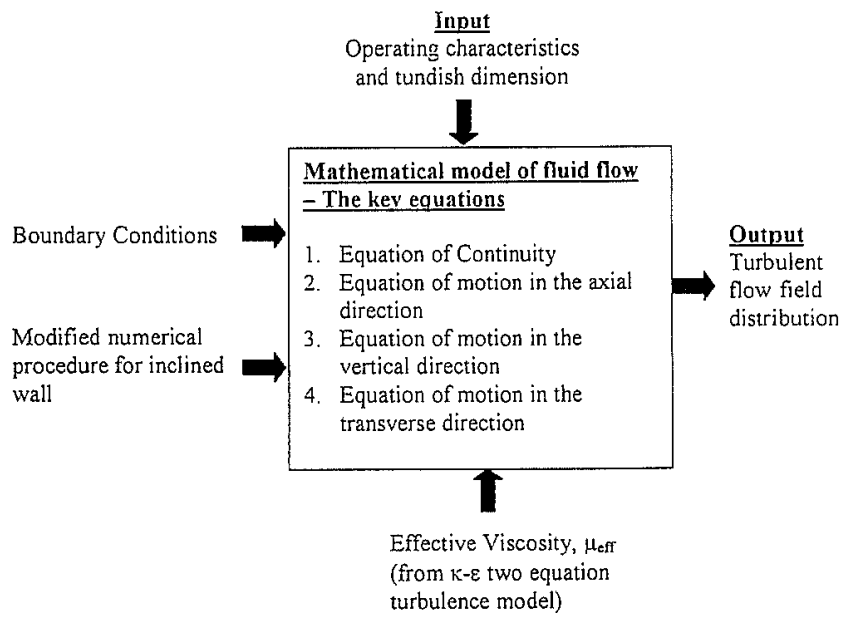

Fig. 11. A schematic of the components of a turbulent flow model as applied to melt flow simulation in tundishes.

unsteady) have therefore, justifiably, been a popular choice for continuous casting tundish systems, and have been the basis for investigating fluid flow and the associated transport processes theoretically. As illustrated schematically in Fig. 11, the turbulent flow model comprises the equation of continuity and a set of three momentum conservation equations for the three coordinate axes $x, y$ and $z$, respectively. The momentum conservation equations embody the effective viscosity, $\mu_{\text {eff }}$, via which the influence of turbulence on the mean flow is accounted for. The distribution of effective viscosity in the flow domain can be calculated from an appropriate turbulence model, for example the popular $k-\varepsilon$ turbulence model of Launder and Spalding. ${ }^{60)}$ In many investigations, ${ }^{37,39,40,46)}$ to model the inclined geometry of the tundish wall or the flow modifiers, such as a dam, a weir, slotted baffles and so on (these are solid obstacles in the flow domain), the flow and the turbulence model equations were modified addopting specific numerical techniques. Although, in these studies, a practically identical set of assumptions were invoked and standard boundary conditions applied at the solid walls, symmetry axis and the free surface, different forms of boundary conditions were considered at the tundish inlet and outlet. For example, steady state velocity fields have been predicted by either prescribing a specified velocity ${ }^{4,46)}$ or a fixed pressure at the tundish outlet. ${ }^{4-45)}$ Similarly, numerical calculations were reported considering fixed value of turbulence kinetic energy and its dissipation rate in the inlet region, ${ }^{42,46)}$ as well as disregarding such a practice. ${ }^{43-45)}$ In spite of such, the results of many numerical investigations carried out to date appear to indicate that predicted flow patterns are relatively insensitive to such minor variations in boundary conditions. By coupling appropriate expressions for conservation of thermal energy, tracer concentration and inclusion population with the turbulent flow model (see Fig. 11), the various transport processes of relevance to tundish systems can be effectively mathematically modelled (see later).

The governing equations of flow, turbulence and the associated transport processes have been solved numerically adapting the finite difference calculation procedure. The numerical solution of the coupled, three dimensional, non-linear, partial differential equations, as is well known, involves extensive computational efforts. Consequently, commercial software packages, rather than custom made ones, have been used frequently by re- 
Table 4. Computational procedure adopted by various investigators to mathematically model transport phenomena in continuous casting tundish systems.

\begin{tabular}{|c|c|c|c|}
\hline Sl. No. & Researchers & Software & Nature of the software \\
\hline 1 & $\begin{array}{l}\text { Illegbussi and coworkers, }{ }^{38.40 .43-45)} \text { Tacke and } \\
\text { Ludwig, }{ }^{42)} \text { Kaufmann et al., }{ }^{57)} \text { Lee } \text { et } \text { al. }^{72)}\end{array}$ & PHOENICS & Commercial \\
\hline 2 & Guthrie and coworkers. ${ }^{54,55,70}$ & METFLO-3D & $\begin{array}{l}\text { Built in-house; } \\
\text { Semi-commercial }\end{array}$ \\
\hline 3 & Hsiao and coworkers ${ }^{67)}$ & $\mathrm{CF}-\mathrm{X} 4$ & Commercial \\
\hline 4 & $\begin{array}{l}\text { Sahai and coworkers, }{ }^{40.41 .51-53.56)} \text { Yeh and } \\
\text { coworkers, }{ }^{63)} \text { Salcudean and coworkers, }{ }^{68)} \\
\text { Hills and coworkers }{ }^{77)}\end{array}$ & $\begin{array}{l}\text { Custom made transient, } \\
\text { three dimensional } \\
\text { turbulent flow model }\end{array}$ & $\begin{array}{l}\text { Models developed in house } \\
\text { by individual group of } \\
\text { researchers }\end{array}$ \\
\hline
\end{tabular}

Table 5. Characteristics of some numerical investigations on tundish system as reported in the literature.

\begin{tabular}{|c|c|c|c|c|c|c|c|c|}
\hline \multirow{2}{*}{ Investigators } & \multirow{2}{*}{$\begin{array}{l}\text { Grid } \\
\text { system\# }\end{array}$} & \multicolumn{3}{|c|}{$\begin{array}{c}\text { Tundish } \\
\text { dimensions, } \mathrm{m}\end{array}$} & \multicolumn{3}{|c|}{$\begin{array}{l}\text { Calculated average } \\
\text { grid spacings, m }\end{array}$} & \multirow{2}{*}{ Tundish } \\
\hline & & $\mathrm{L}$ & $\mathrm{H}$ & W & $\Delta \mathrm{X}$ & $\Delta \mathrm{Y}$ & $\Delta \mathrm{Z}$ & \\
\hline Lai et $a l^{68)}$ & $25 \times 12 \times 14$ & 1.167 & 0.25 & 0.167 & 0.025 & 0.025 & 0.007 & Water model \\
\hline El-Kaddah and Szekely ${ }^{36)}$ & $25 \times 11 \times 11$ & 6.79 & 0.75 & 0.65 & 0.15 & 0.08 & 0.035 & Full-scale \\
\hline He and Sahai ${ }^{41}$ & $30 \times 12 \times 10$ & 1.32 & 0.34 & 0.34 & 0.024 & 0.034 & 0.021 & Water model \\
\hline Illegbussi and Szekely ${ }^{45}$ ) & $25 \times 15 \times 15$ & 1.0 & 0.5 & 0.25 & 0.21 & 0.038 & 0.01 & Water model \\
\hline Joo and Guthrie ${ }^{46)}$ & $40 \times 24 \times 16$ & 7.12 & 1.2 & 0.68 & 0.09 & 0.054 & 0.024 & Full scale \\
\hline Sahai ${ }^{39)}$ & $30 \times 12 \times 15$ & 8.2 & 1.2 & 0.6 & 0.15 & 0.12 & 0.023 & Full scale \\
\hline
\end{tabular}

\# in the symmetrical one quarter of the tundish.

searchers in modelling flows, RTD and associated transport processes in the tundish systems. This is summarised in Table 4 . Of all the commercial software packages, PHOENICS ${ }^{61)}$ however, has found the most wide spread application. It is important to mention here that adapting commercial software packages to the modelling of complex, multidimensional and multiphase flows ensures considerable time savings. It is for such reasons that commercial routines have been popular and are potentially attractive in mathematical modelling studies of tundish systems. On the other hand, since source codes are not provided to the users, there is always the problem if one's intended modelling procedures are actually being performed!

Mathematical model predictions, apart from the various assumptions applied, are a function of numerical parameters, such as the grid distribution, incremental step height (for transient calculations), convergence criteria and so on. The work of Joo and Guthrie ${ }^{46)}$ has demonstrated that numerical grids have considerable influence on the predicted flow fields. Similar conclusions were also drawn by Chakraborty and Sahai ${ }^{48)}$ who noted that the distance of the near wall node, particularly from the base of the tundish along the vertical directions, has a significant influence on the predicted RTD results. These studies ${ }^{46,48)}$ therefore suggest that due care must be taken to ensure practical grid independent solutions (since three dimensional, turbulent flow computations are time intensive, an optimal balance between CPU and accuracy is desirable), before elaborate numerical experimentations are carried out and conclusions drawn therefrom. Numerical simulation of flow and RTD has been reported so far for both reduced, as well as full, scale tundish systems of widely varying geometries and sizes, embodying a variety of grid configurations (typically non-uniform; finer in the vicinity of the inlet and the exit nozzle while relatively coarser in the main body of the tundish). Table 5, in which the characteristics of many numerical studies have been summarised, shows that practically similar grid spacings were used in aqueous and full scale systems. While relatively finer grids were applied in the vertical and the transverse directions, the grid systems in the axial direction have been somewhat coarser. This is to be expected in view of large axial dimensions which tends to make variations in flow less steep. This may also partly be due to a compromise between accuracy and CPU time.

To date, many numerical investigations have been reported in the literature on liquid steel flows in widely varying tundish geometries (viz., rectangular twin port, ${ }^{42}$ ) trough type, ${ }^{46)}$ shallow, ${ }^{45)} \mathrm{T}$ shaped ${ }^{64)}$ etc.) under a wide variety of flow configurations. For example, studies have been reported in which, vertical or inclined walls, ${ }^{41)}$ flow modifiers (viz., dams, weirs, slotted baffles etc.), ${ }^{36,39)}$ electro-magnetic stirring, ${ }^{44,45)}$ auxiliary heating ${ }^{49)}$ etc. have been considered. These studies have, in general, indicated that operating conditions in a tundish profoundly influence the flow. To illustrate this further, predicted flow patterns on the central vertical planes of two strand, symmetrical tundishes have been shown ${ }^{36,39,44)}$ in Figs. 12(a) through 12(c) for three different operating conditions (viz., (a) dam + weir, ${ }^{36)}$ (b) slotted baffle ${ }^{39)}$ and (c) electromagnetic stirring ${ }^{44)}$ ). There, it is readily evident that flows, on a qualitative scale, are remarkably different for the three different configurations. As the rates of the associated transport processes are related to fluid flow, the types of baffles and their specific designs $($ dam + weir $v s$. slotted baffle, etc.), operating conditions 

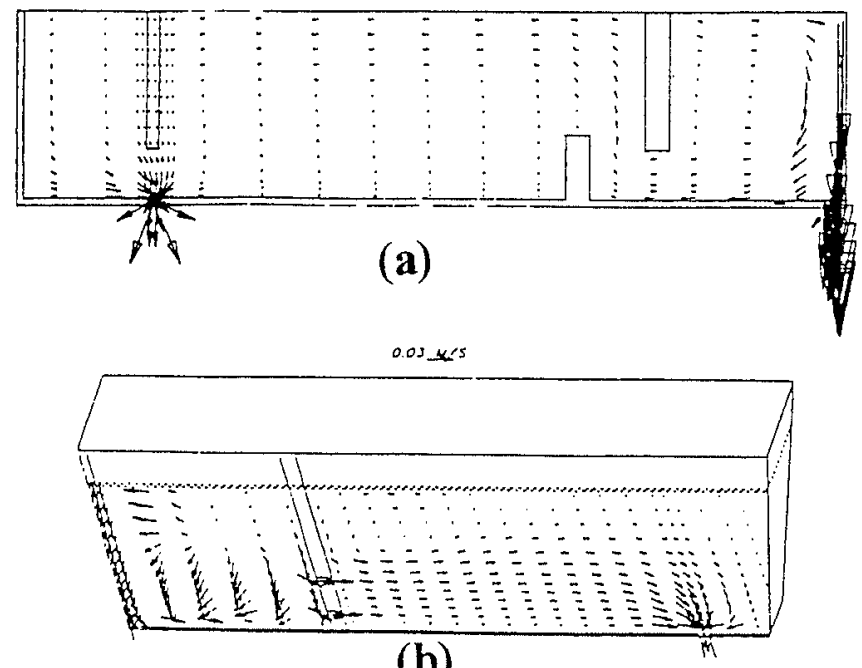

(b)

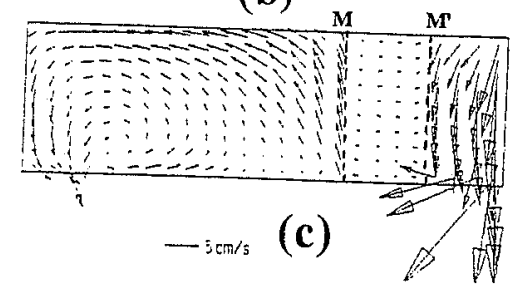

Fig. 12. Influence of tundish designs and operating conditions on the predicted flow patterns in the central vertical plane of two strand slab caster tundish systems (a) the influence of a dam + weir ${ }^{36)}$ (b) the influence of a slotted baffle ${ }^{39)}$ (c) the influence of electromagnetic stirring ${ }^{43)}$ along the line $\mathrm{MM}^{\prime}$.

(with or without electro-magnetic stirring, etc.) are likely to exert considerable influence on the performance (RTD, inclusion separations etc.) of the continuous casting tundish systems.

To evaluate the process performance of continuous casting tundish systems theoretically, residence time distributions (RTD) have been predicted under a wide variety of conditions by mathematically simulating the pulse injection of an inert tracer in to a tundish. To this end, the variation of mass fraction or concentration of an injected tracer, $i$, within the tundish is estimated as a function of time by solving a transient, three dimensional, convection + diffusion equation, ${ }^{39-41,43)}$ viz.,

$$
\begin{aligned}
& \frac{\partial\left(\rho m_{i}\right)}{\partial t}+\frac{\partial\left(\rho u m_{i}\right)}{\partial x}+\frac{\partial\left(\rho v m_{i}\right)}{\partial y}+\frac{\partial\left(\rho w m_{i}\right)}{\partial z} \\
& =\frac{\partial}{\partial x}\left(\Gamma_{\text {eff }} \frac{\partial m_{i}}{\partial x}\right)+\frac{\partial}{\partial y}\left(\Gamma_{\text {eff }} \frac{\partial m_{i}}{\partial y}\right)+\frac{\partial}{\partial z}\left(\Gamma_{\text {eff }} \frac{\partial m_{i}}{\partial z}\right)
\end{aligned}
$$

From the predicted $m_{i}(x, y, z, t)$ field, the variation in exit concentration as a function of the time since addition was made, is estimated so as to derive the characteristic $\mathrm{C}$ curve. Since flow measurements in tundishes are time consuming (because of large tundish volume and considerable spatial variations of velocity), consequently, predicted $\mathrm{C}$ curves have typically been compared with corresponding experimental measurements, ${ }^{48)}$ to assess the validity of the turbulent flow model developed.

In Eq. (21), $\Gamma_{\text {eff }}$ is the effective exchange coefficient and that can be easily derived from a turbulence model (say, the $k-\varepsilon$ turbulence model), assuming an appropriate value of turbulent Schmidt number (often unity). ${ }^{39-41)}$ Standard boundary conditions (these correspond to impervious tundish domain boundaries, across which flux of the injected tracer is assumed to be zero) were applied to solve Eq. (21) numerically. ${ }^{40,43)}$ In addition to these, a fixed value of tracer concentration was applied at one or more of the control volumes in the inlet region as the appropriate initial conditions. No special condition is required at the exit, where the normal velocity ( $=C_{\mathrm{D}} \sqrt{2 g H}$ ) is conventionally specified. This is so since the Peclet number at the outlet is large, making the scalar transport equation exhibit a locally one way behaviour along the vertical $(y)$ direction. As a consequence of such, the grid points associated with the exit nozzle become automatically dissociated from their downstream neighbours.

Thus, applying Eq. (21) in conjunction with the turbulent flow model, Residence Time Distributions in different tundish systems were predicted numerically by various investigators. ${ }^{37,39-41,43,44,48)}$ In these, the influence of various types of flow modifiers, ${ }^{39)}$ tundish wall inclination, ${ }^{41)}$ and electro-magnetic stirring, ${ }^{44)}$ were investigated computationally. As typical examples of these models' capabilities, predicted concentration $v s$. time profiles for two strand slab casting tundish systems, ${ }^{39,40)}$ are shown in Figs. 13(a) and 13(b) respectively. These clearly indicate that RTD parameters ( $v i z ., t_{\min }$, $t_{\text {peak }}$ and $t_{\text {av }}$ ) are related closely to the particular tundish configuration. This is to be expected since flow modifiers, wall inclination, etc. influence the flow patterns, influencing thereby the transport of the added tracer within the tundish (viz., Eq. (21)). Although rigorous comparison between mathematical model predictions and equivalent physical model observations will be addressed in greater detail in the subsequent section, it is to be mentioned here, that mathematical model predictions presented so far compare favourably with experimental observations discussed earlier in Sec. 2(b).

\section{(b) Inclusion Transport and Separation}

By considering a population balance for inclusion particles of the same group characterized principally by their diameter (for spherical particles), Illegbusi and Szekely ${ }^{45}$ have shown that transport of inclusions in tundish systems can be predicted from the following p.d.e:

$$
\begin{aligned}
& \frac{\partial\left(\rho c_{i}\right)}{\partial t}+\frac{\partial\left(\rho u c_{i}\right)}{\partial x}+\frac{\partial\left(\rho\left[v+u_{\mathrm{T}, i}\right] c_{i}\right)}{\partial y}+\frac{\partial\left(\rho w c_{i}\right)}{\partial z} \\
& =\frac{\partial}{\partial x}\left(\Gamma_{\text {eff }} \frac{\partial c_{i}}{\partial x}\right)+\frac{\partial}{\partial y}\left(\Gamma_{\text {eff }} \frac{\partial c_{i}}{\partial y}\right)+\frac{\partial}{\partial z}\left(\Gamma_{\text {eff }} \frac{\partial c_{i}}{\partial z}\right)+S_{i}
\end{aligned}
$$

In Eq. (22), $u_{\mathrm{T}, i}$ is the terminal rise velocity of the particle (derived from the Stokes law e.g., $u_{\mathrm{T}, i}=$ $\left.\sqrt{g d_{\mathrm{p}}{ }^{2} \Delta \rho / 18 \mu}\right)$, the additon of which to the vertical component of fluid motion, $v$, characterises the direct influence of buoyancy on the particles. Similarly, $\Gamma_{\text {eff }}$ is the effective exchange coefficient for transport of 

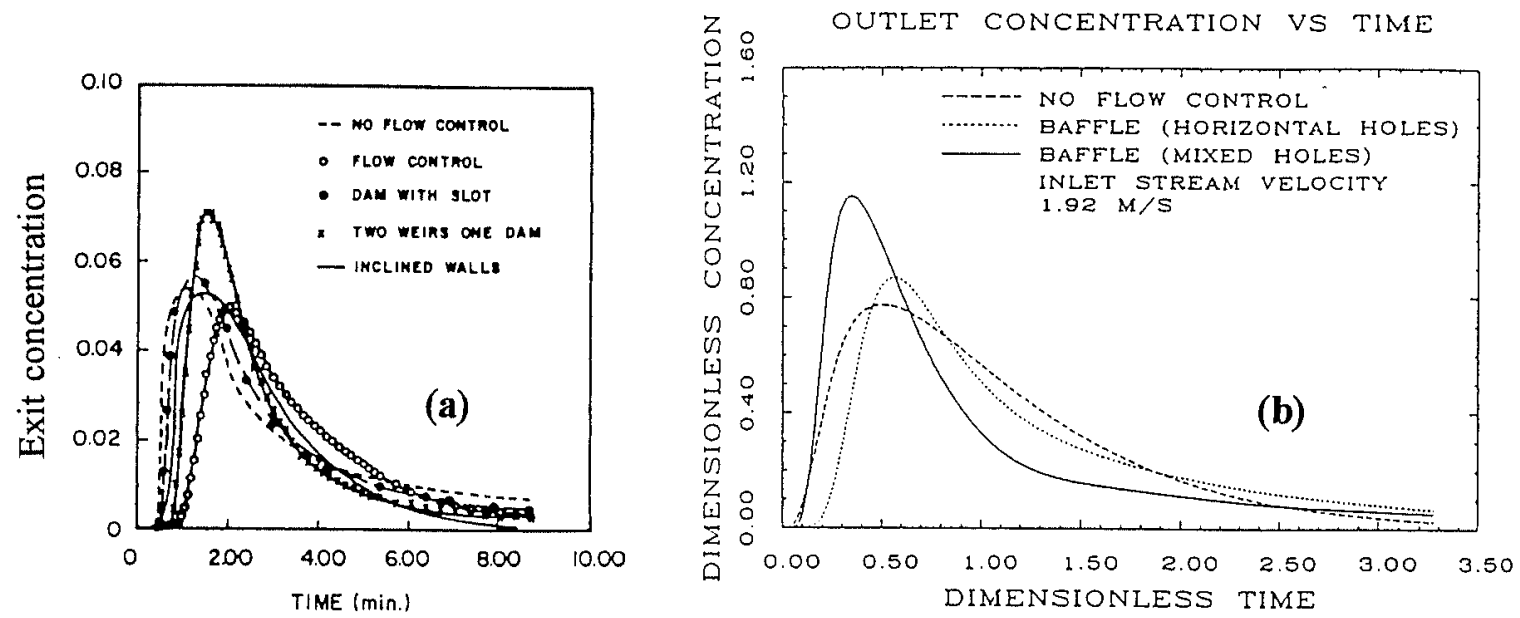

Fig. 13. Predicted variations of the $C$ curves in continuous casting tundish systems illustrating essentially the influence the flow modifiers exert on the RTD (a) after Illegbussi and Szekely ${ }^{40}$ and (b) after Sahai. ${ }^{391}$

Table 6. Details of the boundary conditions and modelling procedures as applied to the numerical simulation of inclusion transport in continuous casting tundishes.

\begin{tabular}{|c|c|c|c|}
\hline \multirow{2}{*}{ Investigators } & \multirow{2}{*}{$\begin{array}{l}\text { Form of inclusion } \\
\text { transport equations }\end{array}$} & \multicolumn{2}{|c|}{ Boundary conditions } \\
\hline & & $\begin{array}{l}\text { At the side and } \\
\text { bottom walls }\end{array}$ & $\begin{array}{l}\text { At the slag-metal } \\
\text { interface }\end{array}$ \\
\hline Illegbussi and Szekely ${ }^{45)}$ & $\begin{array}{l}\text { Transient, multi-particle } \\
\text { model with finite } S_{i}\end{array}$ & $\begin{array}{l}\text { Reflecting wall; flux of } \\
\text { inclusion is zero }\end{array}$ & Ideal absorption, $q_{i}=u_{\mathrm{r}, i} C_{\mathrm{is}}$ \\
\hline Joo et $a l^{46)}$ & $\begin{array}{l}\text { Steady state, single particle } \\
\text { model with zero } S_{i}\end{array}$ & $\begin{array}{l}\text { Reflecting wall; flux of } \\
\text { inclusion is zero }\end{array}$ & Ideal absorption, $q_{i}=u_{\mathrm{T}, i} C_{\mathrm{is}}$ \\
\hline Sinha and Sahai ${ }^{56)}$ & $\begin{array}{l}\text { Steady state, multi-particle } \\
\text { model with finite } S_{i}\end{array}$ & $\begin{array}{l}q_{\mathrm{wsr}}=D_{\text {eff }}(\delta C / \delta 1) ; 1 \text { is the } \\
\text { distance from the nearest } \\
\text { solid surface }\end{array}$ & Ideal absorption, $q_{\mathrm{i}}=u_{\mathrm{T}, i} C_{\mathrm{is}}$ \\
\hline Tacke and Ludwig ${ }^{42)}$ & $\begin{array}{l}\text { Steady state, single particle } \\
\text { with zero } S_{i}\end{array}$ & $\begin{array}{l}\text { Reflecting wall; flux of } \\
\text { inclusion is zero }\end{array}$ & Ideal absorption, $q_{i}=u_{\mathrm{T}, i} C_{\mathrm{is}}$ \\
\hline Kaufmann et al. ${ }^{57)}$ & $\begin{array}{l}\text { Steady state, single particle } \\
\text { with zero } S_{i}\end{array}$ & Not mentioned & Inclusion absorption flux $=u_{\mathrm{T}, i} C$ \\
\hline
\end{tabular}

inclusion, normally set to the value of eddy kinematic viscosity, assuming turbulent Schmidt number to be unity. ${ }^{45,46,56)}$ Finally, $S_{i}$ represents the source/sink term and accounts for the generation or destruction of a particular size of inclusion by coalescence. ${ }^{45,56)}$

Similar equations have been applied by numerous investigators ${ }^{42,45,46,56,57)}$ to predict inclusion population distributions in continuous casting tundish systems. Careful analysis reveals that the exact forms of Eq. (22), together with the associated sets of boundary conditions, varied from one investigation to another. This is summarized in Table 6 where details of the modelling procedures adopted by five different groups of investigators are presented. Referring to Table 6 , it is seen that in all the numerical model studies, an ideal absorption condition has been postulated at the slag-metal interface and accordingly, an outgoing flux was prescribed there. In this regard it is important to mention that conditions at the slag-metal interface can be far from ideal, since inclusion droplets are known to have a dwell time before being absorbed, the latter being a function of the buoyancy and the interfacial forces. ${ }^{62}$ ) In addition to the differences pointed out in Table 6 , a prescribed flux of inclusions $\left(=C_{0} V_{\mathrm{o}}\right)$ at the tundish outlet was also applied in one of the mathematical model studies. ${ }^{56)}$ Outflow boundary conditions, as has been pointed out already, are not required for the solution of convection-diffusion phenomena (say for the transport of turbulence kinetic energy, mass fraction of an added tracer, inclusion population, enthalpy etc.). Consequently, such application ${ }^{56)}$ of an additional flux condition at the tundish outlet, can hardly be justified.

The phenomenon of removal of non-metallic inclusions in continuous casting tundishes has been studied extensively via the numerical solution of Eq. (22). ${ }^{42,45,46,56,57)}$ Thus, by coupling Eq. (22) with an appropriate three dimensional turbulent flow model, the population distribution of inclusions was investigated computationally in different tundish geometries (e.g., $\mathrm{V}$ shaped tundish, ${ }^{57)}$ wedge type tundish, ${ }^{46}$ ) shallow tundish, ${ }^{45)}$ etc.) operating with various kinds of flow modifiers, ${ }^{42,46,56)}$ an electromagnetic stirrer, ${ }^{45)}$ etc. These studies have, in general, indicated that the removal of inclusions from a given tundish is significantly influenced by their terminal rise velocity, $u_{\mathrm{T}, i}$ (a function of particle size and chemistry). Furthermore, the 
Table 7. Numerically predicted total removal rate of various size inclusions under three different conditions (reproduced from Ref. 56)).

\begin{tabular}{|c|c|c|c|c|c|}
\hline Configurations & $\begin{array}{c}\text { Size range, } \\
\mu \mathrm{m}\end{array}$ & $\begin{array}{l}\text { Removed by } \\
\text { sticking, \% }\end{array}$ & $\begin{array}{l}\text { Removed by } \\
\text { collision, \% }\end{array}$ & $\begin{array}{l}\text { Removed by } \\
\text { flotation, } \%\end{array}$ & $\begin{array}{c}\text { Total removed, } \\
\%\end{array}$ \\
\hline \multirow[t]{3}{*}{ No flow control } & $25-40$ & 57.92 & 9.5 & 4.7 & 72.2 \\
\hline & $45-72$ & 56.4 & 0.04 & 16.0 & 72.4 \\
\hline & $75-150$ & 47.65 & 0.00 & 31.0 & 78.7 \\
\hline \multirow[t]{3}{*}{ Dam and weir } & $25-40$ & 53.38 & 10.57 & 4.93 & 68.9 \\
\hline & $45-72$ & 53.31 & 0.08 & 16.15 & 69.5 \\
\hline & $75-150$ & 42.41 & 0.03 & 35.5 & 77.9 \\
\hline \multirow{3}{*}{$\begin{array}{l}\text { Dam, weir and } \\
\text { slotted baffle }\end{array}$} & $25-40$ & 62.96 & 16.60 & 3.55 & 83.1 \\
\hline & $45-72$ & 63.09 & 0.52 & 20.39 & 84.0 \\
\hline & $75-150$ & 58.44 & 0.04 & 33.20 & 91.7 \\
\hline
\end{tabular}

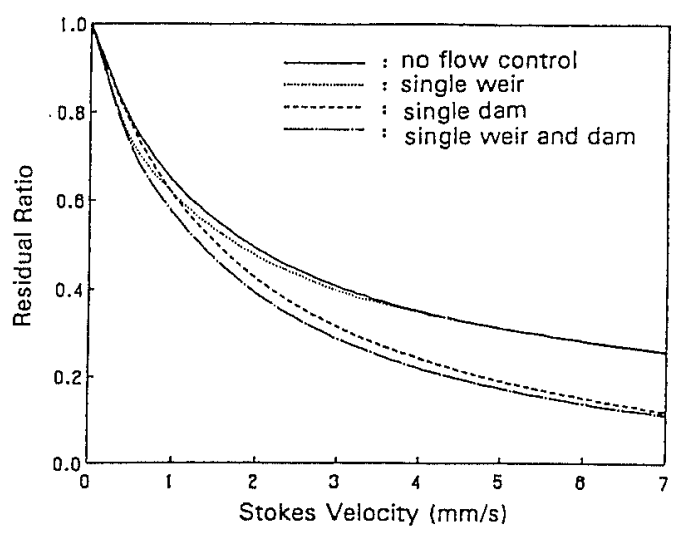

Fig. 14. Predicted inclusion separation ratio (particles in/ particles out) as a function of Stokes velocity for various types of flow modifiers (reproduced from Ref. 46)).

computational work of Sinha and Sahai ${ }^{56)}$ suggests that while larger size inclusions ( $120 \mu \mathrm{m}$ or so) are removed relatively easily by becoming entrapped in the slag phase, small inclusions (approximately $40 \mu \mathrm{m}$ or so in size) do not naturally float up to the slag metal interface. This is readily apparent from the computational results of Sinha and Sahai, which are presented in Table 7. There, it is readily evident that flotation is an important mechanism for the removal of larger size inclusions alone. Similar findings were also reported by Kaufmann ${ }^{57)}$ et al., who computationally observed that only $10 \%$ of the particles with a diameter of $20 \mu \mathrm{m}$ will be separated by buoyancy. Consequently, the necessary conditions for removal of inclusions tabulated earlier in Sec. 2(b) appear to be strictly valid for relatively larger size inclusions (greater than $40 \mu \mathrm{m}$ or so). Based on their computational results, it was postulated by Sinha and Sahai ${ }^{56)}$ that particle coalescence must play an important role in the removal of such smaller size inclusions from the melt. Since the kinetics of inclusion coalescence is influenced by the fluid turbulence, ${ }^{45,56)}$ therefore, turbulence phenomena in tundishes are expected to exert some positive influence on the removal of smaller size inclusions. On the basis of such, providing electromagnetic stirring in the entire tundish which is known to dampen fluid turbulence, ${ }^{45}$ ) may not be helpful in eliminating smaller size inclusions from the melt, as has been anticipated by Illegbusi and Szekely. ${ }^{45)}$
The influence of flow modifiers (dams, weirs, etc.) on inclusion removal was investigated computationally by several investigators. ${ }^{42,46,56,57)}$ The work of Joo et al. ${ }^{46)}$ shows that considerable improvements in inclusion separation (size greater than $40 \mu \mathrm{m}$ or so) is to be expected by applying a suitable combination of dam and weir as flow modifiers in a tundish. This is shown in Fig. 14, which clearly indicates that inclusions with a large terminal rise velocity (in excess of $3 \mathrm{~mm} / \mathrm{s}$ ) (or larger particle diameter, since $d_{\mathrm{p}} \sqrt{u_{\mathrm{T}, i}}$ ) will readily float-up to the slag-metal interface provided appropriate flow modifiers are incorporated into the tundish geometry. Similar trend in results are also evident from Table 7 presented earlier, in which it is seen that the dam and weir configuration leads to some improvement in the removal of larger size inclusions by flotation. It has been suggested ${ }^{56)}$ that the dam and the weir configuration directed the flow towards the surface and as a result increased the floatation flux for this configuration. The work of Joo et al., who investigated separation of inclusions in the size range of $20-120 \mu \mathrm{m}$ in different shaped tundishes also shows that removal of smaller size inclusions from the tundish is relatively insensitive to the basic tundish geometry, corresponding removal rates for larger size inclusions exhibit considerable dependency on tundish geometry. Similar observations were reported by Tacke and Ludwig, ${ }^{42)}$ who also noted that the dimensions of the tundish have some influence and that increased width promotes enhanced inclusion separation (presumably for larger size inclusions, $100 \mu \mathrm{m}$ dia. or so).

On the basis of the preceding discussion it is readily apparent that size of inclusions plays a key role in their separation and therefore, determine the effectiveness of a given tundish and flow modifier designs. The present authors note that in many of the computational and experimental studies reported in the literature, the subject of inclusion removal has been addressed, with no specific reference to inclusion size. Consequently, in implementing findings from such studies or analysing the results, appropriate care must be taken. Interestingly, the computational results of Sirha and Sahai presented in Table 7 suggest that sticking to the solid surface is the dominant mechanism of inclusion removal (in comparison to flotation or collision) from a tundish for smaller and bigger inclusions alike. Such computational results are yet to be verified against experimental observations. 
Table 8. Details of the conditions considered by various investigators to numerically compute temperature fields in continuous casting tundish systems.

\begin{tabular}{|c|c|c|c|c|}
\hline \multirow{2}{*}{ Investigators } & \multirow{2}{*}{$\begin{array}{l}\text { Computational } \\
\text { conditions }\end{array}$} & \multirow{2}{*}{$\begin{array}{c}\text { Initial melt } \\
\text { temperature, }{ }^{\circ} \mathrm{C}\end{array}$} & \multicolumn{2}{|c|}{ Boundary conditions } \\
\hline & & & Free surface & Walls \\
\hline $\begin{array}{l}\text { Illegbussi and } \\
\text { Szekely }^{45,49)}\end{array}$ & Steady & 1600 & $\begin{array}{l}\text { Combined conduction } \\
\text { and radiation with } \\
T_{\mathrm{a}}=600 \mathrm{~K}\end{array}$ & All walls insulated \\
\hline $\begin{array}{l}\text { Chakraborty and } \\
\text { Sahai }^{51-53)}\end{array}$ & $\begin{array}{l}\text { Steady as well } \\
\text { as transient }\end{array}$ & $\begin{array}{l}1567 \text { and time varying } \\
\text { initial temperature } \\
\text { field }\end{array}$ & $15 \mathrm{~kW} / \mathrm{m}^{2}$ & $\begin{array}{l}3.2,3.8 \text { and } 2.3 \mathrm{~kW} / \mathrm{m}^{2} \text { at } \\
\text { longitudinal, transverse and } \\
\text { bottom walls }\end{array}$ \\
\hline Joo et al. ${ }^{46.54 .551}$ & Steady & 1580 & $75 \mathrm{~kW} / \mathrm{m}^{2}$ & $2.6 \mathrm{~kW} / \mathrm{m}^{2}$ at all the walls \\
\hline
\end{tabular}

\section{(c) Thermal Energy Transport}

Heat loss, and its associated influence on liquid steel flow, RTD, temperature stratification, etc. in continuous casting tundish systems have been the subject of a large number of mathematical modelling investigations. ${ }^{47,49-54,65)}$ So far, to mathematically model various thermal phenomena, three different types of models have commonly been applied. These include,

(i) macroscopic (or, algebraic) models, ${ }^{47,64)}$

(ii) expert system based input-output model, ${ }^{50)}$ and

(iii) differential models. ${ }^{49-54)}$

Macroscopic modelling provides information on the time evolution of bulk steel temperatures in a given tundish during the casting process. Such models are typically semi-empirical as these embody many adjustable parameters. On the other hand, in expert system based models, the expertise, which forms the knowledge base of the model, is expressed as a set of simple, heuristic, "if-then" statements in the form of a decision tree. This class of model is inherently empirical in nature.

In contrast to the above, the differential models are based on the fundamental laws of heat transfer and are aimed at providing increased understanding and better insight into the overall thermal energy transport process. In the presence of a three dimensional velocity field $u, v$ and $w$, the appropriate statement for conservation of thermal energy under steady state condition can be expressed in terms of the Cartesian co-ordinate system as:

$$
\begin{aligned}
& \frac{\partial\left(\rho u T C_{\mathrm{p}}\right)}{\partial x}+\frac{\partial\left(\rho v T C_{\mathrm{p}}\right)}{\partial y}+\frac{\partial\left(\rho w T C_{\mathrm{p}}\right)}{\partial z} \\
= & \frac{\partial}{\partial x}\left(k_{\text {eff }} \frac{\partial T}{\partial x}\right)+\frac{\partial}{\partial y}\left(k_{\text {eff }} \frac{\partial T}{\partial y}\right)+\frac{\partial}{\partial z}\left(k_{\text {eff }} \frac{\partial T}{\partial z}\right) . .
\end{aligned}
$$

In Eq. (23), $k_{\text {eff }}$ is the effective thermal conductivity and is deduced from a turbulence model assuming an appropriate value of the turbulent Prandtl Number (assumed to be equal to 0.9 for liquid steel). ${ }^{49)}$

Thermal fields in continuous casting tundish systems have been predicted for a wide variety of conditions embodying Eq. (23) with appropriate flow equations and turbulence models. In these studies, different boundary conditions were applied at the tundish wall and free surfaces to seek the numerical solutions. The set of boundary conditions considered by three different groups of investigators are summarized in Table 8 . This shows that although heat losses through the tundish free surface was accounted for in all the studies, markedly different values were applied there by the various set of investigators. Furthermore, while Chakraborty and Sahai ${ }^{51-53)}$ as well as Joo et al. ${ }^{46,54)}$ assumed finite heat losses through the tundish side and bottom walls, Illegbusi and Szekely ${ }^{49)}$ considered a perfectly insulated tundish. In addition to these, widely varying initial temperature fields were applied in the numerical solution schemes. ${ }^{46,49,51-54)}$ As a consequence of these, some variations in predicted results, as reported by various investigators, can be anticipated. It is to be mentioned here that wall heat flux values proposed by Chakraborty and Sahai ${ }^{51-53)}$ as well as Joo et al. ${ }^{46,54)}$ have been the basis of many subsequent computational studies of heat transfer phenomena in continuous casting tundish systems. ${ }^{66,67)}$

In practically all the studies reported in this area, Eq. (23) has been coupled to the flow equations, incorporating Boussinesque's term (i.e., $\rho g \beta \Delta T$ ) into the vertical direction momentum balance equation. ${ }^{49,51-54)}$ This is so since the value of $N_{\mathrm{Gr}} / N_{\mathrm{Re}}{ }^{2}$ in the tundish systems has been known to be much greater than unity. ${ }^{46,67)}$ This essentially implies that free convection effects in tundishes are important in the calculation of flow fields. This is illustrated via Fig. 15, in which equivalent flow patterns at the central vertical plane of an unbaffled tundish are compared under athermal and isothermal conditions respectively. ${ }^{51-53)}$ There, considerable differences, between the two set of predicted results is readily apparent.

The influence of various types of flow modifiers on temperature fields was investigated computationally by Joo et $a l^{46,54,55)}$ in widely varying tundish geometries. Their results ${ }^{46,54,55)}$ show that flow modifiers do not much influence the extent of temperature drop between the inlet and the outlet in a given tundish under steady state conditions. This is illustrated in Fig. 16. This is to be expected since the same heat loss to the walls were applied and the radiative losses were essentially the same in the numerical calculation scheme. More importantly, the flow modifiers affected the residual ratio for inclusion removal, by increasing the intermixed volume. In contrast, the geometry of the tundish was found to have some influence on the extent of such temperature drops. In a separate computational work, Illegbussi and Szekely, ${ }^{49)}$ based on their mathematical model results, suggested that an adequate way of compensating for such 

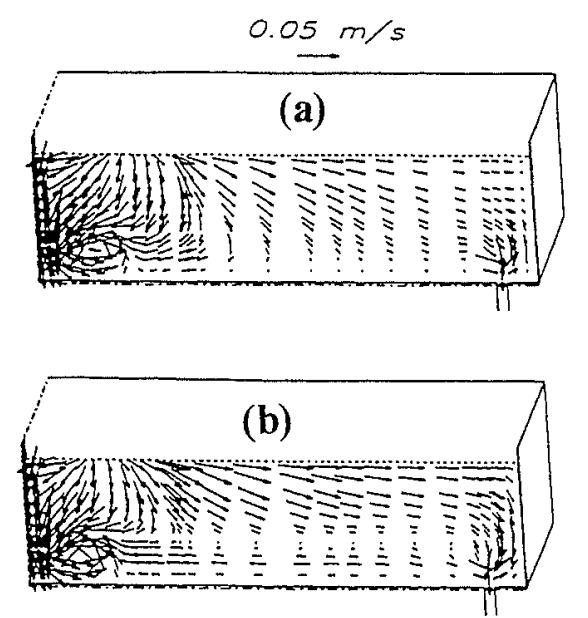

Fig. 15. Predicted flow pattern in the central vertical plane of a continuous casting tudish under steady state (a) ignoring free convection effects (isothermal) and (b) considering free convection effect (athermal). ${ }^{51}$
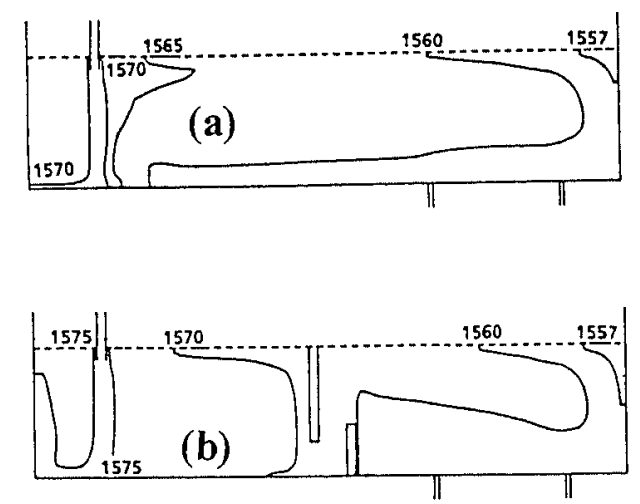

Fig. 16. Predicted temperature isotherms in a twin port tundish under steady state conditions to illustrate the influence the flow modifiers exert on the extent of temperature drop. (a) with no flow modifiers and (b) with a dam + weir. ${ }^{55)}$

temperature drops is through the provision of auxiliary heating in tundishes. In that context, it was shown by those authors ${ }^{49)}$ that the type of heater(s) as well as their location(s) within the tundish, are critical to the rate at which heat can be transferred from such a source to the liquid steel melt. The authors ${ }^{49)}$ noted that while a quiescent melt, less turbulence, etc. are conductive to the removal of relatively larger size non-metallic inclusions in the tundishes, these conditions are likely to be far from ideal as far as absorption of heat through the free surface and the subsequent transport within the melt is concerned. Under such conditions, obviously, the operating parameters are required to be optimised so as to ensure maximum inclusion removal coupled with efficient thermal mixing within the melt.

Transient thermal phenomena such as a variable temperature in the incoming liquid steel stream, ladle or grade change operations, etc., which are of considerable practical importance, were investigated theoretically by Sahai and coworkers. ${ }^{51-53,59)}$ It has been computationally observed by these authors ${ }^{51-53)}$ that during ladle change operations, although the depth of liquid in the tundish changes somewhat, the flow pattern of liquid steel remains similar to that expected under steady state conditions. Computational results of Chakraborty and Sahai ${ }^{51)}$ also show that the protective thermal cover on ladles are beneficial, and has the potential to reduce the extent of thermal loses from an uncovered tundish.

\section{Combined Physical and Mathematical Modelling Studies}

In many studies, ${ }^{63-78)}$ mathematical models, in conjunction with appropriately scaled down physical models have been applied to investigate various transport process of relevance to continuous casting tundish systems. To date, a large number of combined theoretical and experimental investigation on widely varying aspects of tundish metallurgy, such as hydrodynamics, ${ }^{63,64,68,72)}$ RTD ${ }^{69,74,75)}$ turbulence modelling, ${ }^{48,58)}$ thermal energy transport, ${ }^{66,67,70,71,77,78)}$ inclusion transport and separation, ${ }^{70,73)}$ etc., have been carried out and reported on. In these, considerable efforts have been made to develop a reliable and predictive mathematical frame work which can be conveniently extrapolated to investigate relevant phenomena in the corresponding industrial systems.

Numerical computation of fluid flow, together with corresponding experimental measurements in reduced scale water models have been reported by several investigators. ${ }^{68,41,72)} \mathrm{He}$ and Sahai ${ }^{411}$ carried out flow visualisation with Pliolite (a plastic resin, sp. gr. $=1.04$ ) particles in aqueous tundish systems and noted that their measurements (extremely limited) are in good agreement with predicted results. Relatively more detailed flow measurements in tundish systems were reported by Lai et al. ${ }^{68)}$ These authors, using LDV, demonstrated that overall fluid flow patterns in tundish systems can be mathematically simulated reasonably well via their steady state three dimensional turbulent flow model. It was also pointed out by these authors ${ }^{68)}$ that in some selected regions within the model tundish, predicted and experimental flows are not in good agreement either qualitatively or quantitatively.

To date, the most extensive measurements and comparison between predicted and experimental flow patterns in water model tundish systems have been due to Lee et al. ${ }^{72)}$ Their results, reproduced from Ref. 72), are illustrated in Fig. 17, in which, predicted and experimental flow patterns on three different longitudinal vertical planes of a single strand slab caster tundish system have been compared directly. There, theory supported by experimental evidence, clearly show that fluid flow in a tundish system is three dimensional in nature with considerable spatial variations. On the basis of the comparison illustrated in Fig. 17, while it can be concluded that predicted and experimental flow patterns are very similar, careful and close examination of the same reveals some discrepancies. For example, the predicted flow is somewhat faster in the bulk of tundish than the experimental measurements. Similarly, in some localised regions the predicted and experimental flow patterns are strikingly dissimilar. It is to be mentioned here that similar conclusions also follow from their ${ }^{72)}$ other set of results presented for tundish systems operated 


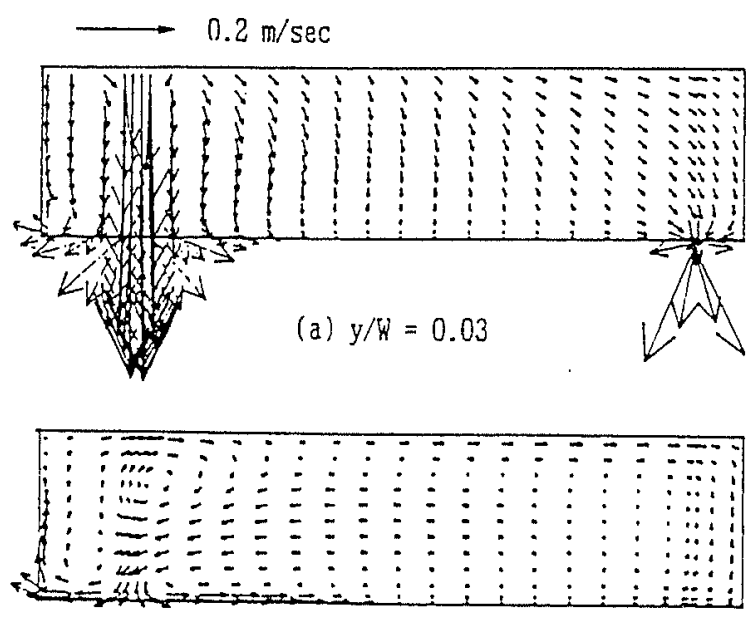

(b) $y / w=0.50$

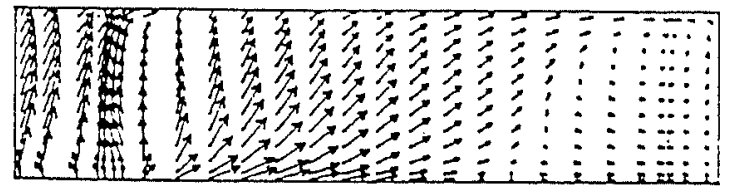

(c) $y / w=0.97$

Computed

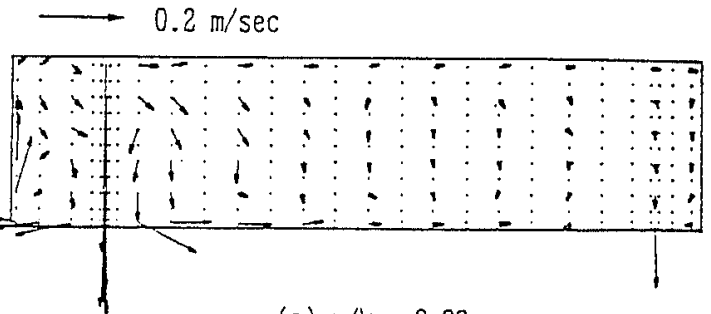

(a) $y / w=0.03$

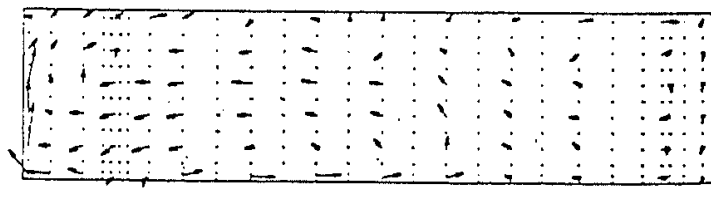

(b) $y / w=0.50$

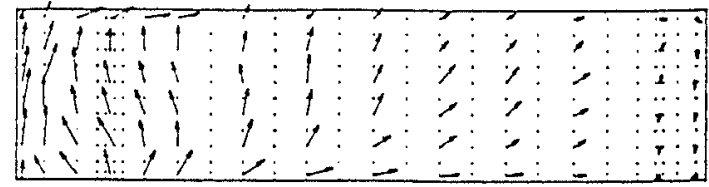

(c) $y / w=0.97$

Measured

Fig. 17. Numerically predicted velocity fields in three different longitudinal vertical plane of a single strand water model tundish system and their comparison with those measured experimentally. ${ }^{72}$ )

with a dam + weir combination.

There can be several reasons for such a discrepancy between the predicted and experimental flow patterns. According to the present authors, the procedure adopted to model (i) the near wall region in a tundish with inclined frontal and side walls as well as (ii) turbulence phenomena in the system, are likely to the possible reasons for such a discrepancy. As pointed out in the previous section, it was demonstrated computationally ${ }^{48}$ that the distance of the near wall node from the base of the tundish has profound influence on their predicted RTD. Furthermore, modelling of flow and turbulence phenomena in tundishes with inclined wall, poses an additional problem, owing to the uncertainties and approximations associated with the application of the wall function procedures. Compounding these uncertainties, it has been considered by many investigators ${ }^{22,36,49,58)}$ that barring the regions associated with the inlet and the outlet, fluid motion in bulk of the tundish is quasi-turbulent. Despite such apprehensions, practically all the computational studies on tundish systems have been carried out incorporating the $k-\varepsilon$ turbulence model of Launder and Spalding, ${ }^{60)}$ which is essentially applicable to high Reynolds number flow situations. Towards these, it is important to note here that except for the study of Lai et al., ${ }^{68)}$ not much information is available on the measurements of turbulence kinetic energy in tundish systems. Consequently, it is not known with any certainty, how well turbulence phenomena in tundishes are simulated by the $k-\varepsilon$ turbulence model. ${ }^{60}$

In a numerical model investigation of turbulent flow phenomena, Illegbussi ${ }^{58)}$ has shown that the high Reynolds number version of the $k-\varepsilon$ turbulence model overpredicts mixing in the tundishes and leads to longer minimum breakthrough times than are observed experimentally. Similar observations were also recorded by Camplin et al. ${ }^{71)}$ as well as Chen and Pehlke. ${ }^{74)} \mathrm{It}$ was further demonstrated by the same author ${ }^{58)}$ that by using a two fluid model for turbulence phenomena, that takes into account the coexistence of a turbulent and non-turbulent fluid in the tundish, such discrepancies between experimental observation and numerical predictions can be considerably minimised. Although the adequacy of the two fluid turbulence model has been demonstrated with reference to RTD parameters only, direct evidence on the role played by such a model in bringing the predicted and experimental flow closer, is currently lacking. In view of the above, it is perhaps worthwhile to examine the adequacy of low Reynolds number version of the $k-\varepsilon$ turbulence model to the hydrodynamic modelling of tundish systems. The low Reynolds number turbulence model, as one would note here, would be particularly advantageous and have an edge over their high Reynolds number counterpart, since the former class of models can simulate the near wall (typically inclined) regions without wall functions and hence do away with undue approximations and uncertainties. Needless to mention, low Reynolds number turbulence models require somewhat finer grids in the vicinity of the solid walls and are therefore prone to increase CPU times somewhat.

As discussed already in the two preceding sections, numerous physical and mathematical modelling studies have been carried out and reported on in the literature on tracer dispersion phenomena in continuous casting tundish systems. Thus, while Chakraborty and Sahai ${ }^{48)}$ 


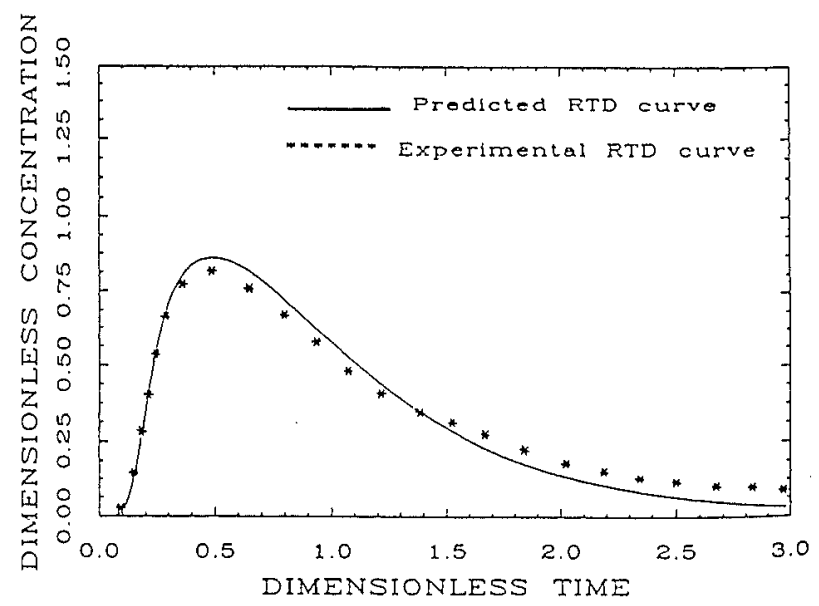

Fig. 18. Numerically predicted and experimentally measured "C" curves. ${ }^{48}$ )

assessed directly the numerically predicted exit concentration vs. time curve against their experimental measurements, comparisons between experimental and predicted minimum break through time has been reported by Illegbusi et al., ${ }^{69)}$ Camplin et $a .^{71)}$ as well as Chen and Pehlke. ${ }^{74)}$ In Fig. 18, a comparison between numerically predicted " $\mathrm{C}$ " curve for a single strand slab casting water model tundish with corresponding experimental measurements ${ }^{48}$ ) has been illustrated. There, close agreement between theoretical and experimental C curves, is at once apparent. Such agreement, as has been demonstrated computationally, depends strongly on the numerical grid distribution, the distance of the near wall node from the bottom of the vessel being particularly critical. ${ }^{48)}$ In contrast, theoretically predicted and experimentally measured minimum break through times, were found to correspond somewhat less satisfactorily, with the mathematical models, in general, predicting longer breakthrough times. ${ }^{69,71,74)}$ Nevertheless, on the basis of evidence presented so far, ${ }^{48,58,69,71,74)}$ it can be concluded that convection diffusion phenomena such as the dispersion of an inert tracer in tundish systems can be mathematically modelled with reasonable certainty through the numerical solution of Eq. (21). In the absence of rigorous validation of the mathematical model with direct flow or turbulence kinetic energy measurements, such evidence ${ }^{48,68,70,73)}$ within the literature implicitly demonstrates the general adequacy of the mathematical models applied to investigate transport phenomena in continuous casting tundish systems.

Extensive mathematical modeling of thermal phenomena in continuous casting tundish systems, as has been pointed out already in Sec. 3(c), has been reported in the literature. In contrast to such theoretical efforts, not much experimental work has been carried out to assess the reliability of the thermal models developed. Nevertheless, in a limited range of temperature, the adequacy of thermal model predictions were assessed by Sheng et al. ${ }^{67)}$ who carried out experiments in aqueous tundish models using hot and cold water. In their study, ${ }^{67)}$ a set of thermocouples were embedded at various locations to measure temperature distribution in the tundish in order to assess the predictive capabilities
Table 9. Comparison of inclusion floatation results with experimental observations (reproduced from Ref. 56)).

\begin{tabular}{ccccc}
\hline $\begin{array}{c}\text { Experimental } \\
\text { set }\end{array}$ & $\begin{array}{c}\text { Tundish } \\
\text { configurations }\end{array}$ & $\begin{array}{c}\text { \% removal } \\
\text { predicted } \\
\text { by model }\end{array}$ & $\begin{array}{c}\text { \% removal } \\
\text { experimental }\end{array}$ & $\begin{array}{c}\text { Particle } \\
\text { size, } \mu \mathrm{m}\end{array}$ \\
\hline A & $\begin{array}{c}\text { No flow } \\
\text { control } \\
\text { Weir only }\end{array}$ & 20.0 & 18.7 & 40 \\
& Dam + Weir & 18.6 & 20.0 & 40 \\
& B flow & 67.6 & 18.5 & 40 \\
\hline B & control & 75.2 & 64.0 & 80 \\
& Dam + Weir & 78.0 & 80 \\
\hline
\end{tabular}

of a non-isothermal turbulent flow model. On the basis of such measurements, it was demonstrated by Sheng and coworkers ${ }^{67)}$ that free convection effects are important and therefore, likely to have significant influence on the flow patterns produced in a tundish. As a consequence of such, it was suggested that flow patterns in industrial tundish systems are expected to be a consequence of both free and forced convection phenomena. Similar observations were also made by Joo and Guthrie ${ }^{46)}$ in a previous study. Similarly, the combined experimental and theoretical study carried out by Morales et $a l .{ }^{66)}$ shows that the extent of temperature drop between the inlet and exit in actual industrial scale caster tundish can be predicted reasonably accurately from an appropriate thermal energy balance model ${ }^{51-53)}$ (viz., Eq. (23)).

Mathematical modelling studies on inclusion transport and separation in tundish systems have also been numerous. The reliability of the models developed is often not known, since comparison between theoretical prediction and experimental measurements have been limited. Studies in the open literature on the removal of inclusions from industrial systems are practically absent ${ }^{19)}$ and experimental trials on aqueous models have been relatively few. ${ }^{10,11)}$ In a recent publication, Sinha and Sahai ${ }^{56)}$ attempted to validate their inclusion transport model (see Sec. 3(b)) against the two set of experimental measurements reported in the literature. ${ }^{10,11)}$ As shown in Table 9, the agreement between theoretically predicted inclusion removal rates and the corresponding experimental observations appear to be very reasonable. As of now, it is not known with any certainty how well the various inclusion transport models ${ }^{42,45,46,56,57)}$ simulate conditions in actual caster tundish systems. More theoretical and experimental work is required to assess the adequacy of inclusion transport models, particularly with reference to the plant scale operations.

The many investigations carried out to date and considered in the review evidently demonstrate that useful inferences on plant scaled tundish performance can be made from observations derived from appropriately scaled down water models. ${ }^{14,17,19)}$ Similarly, numerous mathematical modelling studies discussed in this section, appear to indicate that a reasonably accurate mathematical framework now exists ${ }^{48,67,68)}$ for predict- 


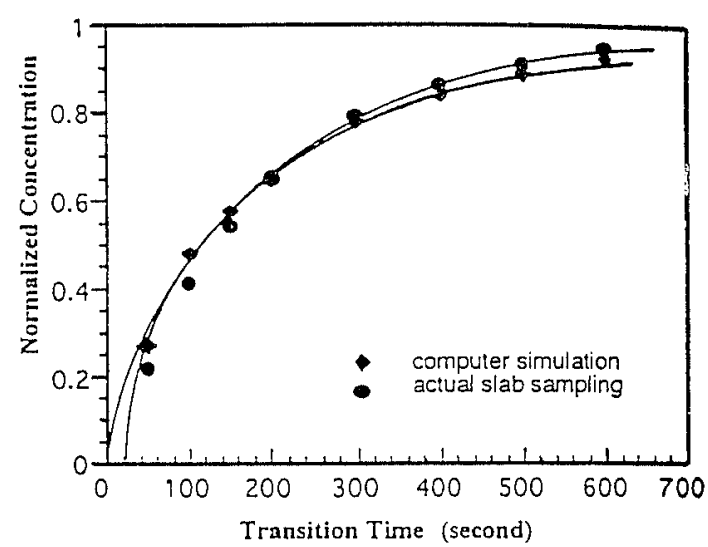

Fig. 19. Numerically predicted concentration field at the tundish exit as a function of time during a typical grade change operation and their comparison with those measured from an industrial scale slab caster. ${ }^{741}$

ing flow, RTD and the associated transport processes from first principles. Of particular significance here are the studies which directly correlate results from either a physical model or a mathematical model with actual plant scale data ${ }^{14,19,65,74)}$ as these lend direct credibility to the mathematical model study program. One such final illustration, reproduced from the work of Chen and Pehlke ${ }^{74)}$ is shown as Fig. 19, in which, numerically predicted concentration field at the tundish exit during a grade transition has been directly compared with measurements made from an actual caster tundish. Close agreement between prediction and industrial measurements, as reflected in Fig. 19, evidently demonstrates the effectiveness of the model study program, and the approach adopted to investigate multiphase, turbulent, difficult to investigate, steelmaking reactors, such as the continuous casting tundish.

\section{Concluding Remarks}

Numerous experimental and theoretical studies have been carried out using both aqueous models and industrial units to investigate various transport phenomena (RTD, inclusion separation, heat loss and temperature drop, grade intermixing, etc.) of relevance to continuous casting tundish systems. In these, a wide range of tundish geometries (Rectangular, V shaped, T shaped, skewed delta shaped, single vs. multiple strand, etc.) in conjunction with numerous designs of flow modifiers (dam, weir, slotted baffles, pouring pad, etc.) were applied to investigate primarily the flotation of inclusions from tundishes as a function of operating variables. In addition to such, the role of increased throughput rate, electro-magnetic stirring and auxiliary heating, on tundish performance were also investigated. As a result of these, the influence such operating variables exert under practical conditions are now known with a reasonable amount of certainty.

The large number of physical and mathematical studies considered in this work appear to indicate that flow conditions conducive to the float out of non-metallic inclusions from tundishes can be created inserting appropriate flow modification devices. However, the optimal design of such flow modifiers and their location within a tundish is likely to depend on the tundish geometry and the operating conditions (hence would vary from one practice to another) and is very dependent on the size range of inclusions present within the molten steel. Thus producer A with inclusions less than $20 \mu \mathrm{m}$ will find dams and weirs to be of little merit, while producer B with inclusions ranging from $20-120 \mu \mathrm{m}$ will find great improvement.

Mixing, both thermal and material, on the other hand, require significantly different flow conditions (in relation to those required for inclusion float out). Consequently, in arriving at the optimal flow modifiers or operating conditions, the objective of liquid steel treatment in tundish must be defined a-priori. It has been suggested by various investigators ${ }^{10,11,17,19,27)}$ that flotation of larger size inclusions (greater than $40 \mu \mathrm{m}$ or so) can be qualitatively assessed through flow visualisation studies and RTD measurements.

The present review clearly indicates that useful inferences on industrial tundish performance can be made from observations derived from reduced scale water models. Similarly, extensive mathematical modelling of fluid flow and the associated transport phenomena and the concurrent validation of mathematical model predictions against laboratory, as well as plant scale experimental data, indicate that a reasonably accurate mathematical frame work now exists to effectively carry out design and process analysis calculations in continuous casting tundish systems.

\section{Nomenclature}

$C$ : Concentration of inclusion population

$C_{\mathrm{D}}$ : Nozzle discharge coefficient

$C_{\mathrm{o}}$ : Inclusion concentration at the outlet

$C_{\mathrm{p}}:$ Specific heat

$C_{\text {is }}$ : Concentration of inclusion at the slag-metal interface

$\mathrm{d}_{\text {noz }}:$ Ladle shroud nozzle diameter

$E(t)$ : The Residence Time Distribution Functions

$g$ : Acceleration due to gravity

$H$ : Depth of liquid in the tundish

$k$ : Turbulence kinetic energy

$k_{\text {eff }}$ : Effective (molecular + turbulent) thermal conductivity

$L$ : Length of the tundish

$L_{\mathrm{c}}$ : Characteristic length of the tundish

$m_{i}$ : Mass fraction of the injected tracer, $i$

$\Delta m_{i}$ : Infinitismal amount of mass of the tracer flowing out through strand $i$ in time $\Delta t$

$N_{\text {Eu }}$ : Euler Number

$N_{\mathrm{Fr}}$ : Froude Number

$N_{\mathrm{Re}}$ : Reynolds Number

$N_{\mathrm{Re}, \mathrm{l}}$ : Turbulent Reynolds Number

$N_{\mathrm{Pr}, \mathrm{t}}:$ Turbulent Prandtl Number

$N_{\mathrm{Gr}}$ : Grashoffs Number

$N_{\text {in }}$ : Number density of particles carried into the tundish via the inlet

$N_{\text {out }}$ : Number density of particles carried out of the tundish through the outlet 
$p:$ Dynamic pressure

$q_{\text {wsf }}$ : The wall sticking flux of inclusions

$Q$ : Volumetric flow rate of liquid into (or out of) tundish

$Q_{\mathrm{a}}$ : Liquid flow rate through the active region of the tundish

$S_{i}$ : Volumetric rate of generation or destruction of inclusions belonging to the group $i$

$t:$ Time

$T_{\mathrm{o}}:$ A reference temperature

$T_{\mathrm{a}}$ : Ambient temperature

$u$ : Component of liquid velocity along the length of the tundish

$u_{\mathrm{r}, i}$ : Relative velocity between inclusion (characterised by size $i$ ) and the surrounding fluid

$u_{\mathrm{T}, i}$ : Terminal rise velocity of inclusion belonging to the group $i$

$U:$ A characteristic velocity

$U_{\text {in }}$ : Vertical inlet velocity into the tundish

$v$ : Component of liquid velocity along the vertical direction

$V_{0}$ : Vertical outgoing velocity at the tundish outlet

$V_{\mathrm{dv}}:$ Dead volume fraction

$V_{\mathrm{pv}}$ : Plug volume fraction

$V_{\mathrm{dpv}}$ : Dispersed plug volume fraction

$V_{\mathrm{mv}}:$ Well mixed volume fraction

$w$ : Component of liquid velocity along the width of the tundish

$W:$ Width of the tundish

$x, y, z$ : Three co-ordinate axes

Greek symbols

$\beta$ : Coefficient of volumetric thermal expansion

$\varepsilon$ : Dissipation rate of turbulence kinetic energy

$\mu$ : Viscosity of liquid

$\lambda$ : Geometrical aspect ratio

$\tau$ : Theoretical residence time or nominal holding time

$\theta:$ Dimensionless time $(=t / \tau)$

$\rho:$ Density of liquid

$\Gamma:$ Exchange coefficient for tracer dispersion or inclusion transport phenomena

Subscript and superscript

mod: Model

f.s: Full scale

min: Minimum

peak: Peak or highest value

a or av: Average

eff: Effective

\section{REFERENCES}

1) J. Szekely and O. J. Illegbussi: The Physical and Mathematical Modelling of Tundish Operations, Springer Verlag, New York, (1989).

2) L. J. Heaslip, A. McLean and I. D. Sommerville: Continuous Casting, Vol. 1, ISS of AIME, (1983).

3) J. Schade: Tundish Metallurgy, Vol. 1 \& 2, ISS of AIME, (1991).

4) A. McLean: Proc. of the Steelmaking Conf., (1988), 3.

5) J. Tsubokura, I. D. Sommerville and A. McLean: Iron Steelmaker, 12 (1985), 58

6) J. Tsubokura, I. D. Sommerville and A. McLean: Iron Steelmaker, 12 (1985), 43.
7) J. Tsubokura, I. D. Sommerville and A. McLean: Iron Steelmaker, 12 (1985), 48.

8) J. Tsubokura, I. D. Sommerville and A. McLean: Iron Steelmaker, $12(1985), 43$

9) J. Tsubokura, I. D. Sommerville and A. McLean: Iron Steelmaker, 12 (1985), 44.

10) F. Kemeny, D. J. Harris, A. McLean, T. R. Meadowcroft and J. D. Young: Proc. of the 2nd Process Technology Conf., TMS, Warrendale, PA, (1981), 232.

11) H. Nakajima, F. Sebo, S. Tanaka, I. Dumitru, D. J. Harris and R. 1. L. Guthrie: Proc. of the Steelmaking Conf., TMS, (1986), 705.

12) J, Knoepke and J. Mastervich: Proc. of the Steelmaking Conf., TMS, (1986), 777.

13) Y. Sahai and R. Ahuja: lronmaking Steelmaking, 13 (1986), 241.

14) E. Martinez, M. Maeda, L. J. Heaslip, G. Rodriguez and A. McLean: Trans. Iron Steel Jpn., 26 (1986), 724.

15) S. Govindarajan, R. Dutta and A. Chatterjee: Proc. of the Sixth Int. Iron and Steel Cong., ISIJ, Tokyo, 3 (1990), 197.

16) S. Dawson: Proc. of the Steelmaking Conf., TMS, Warrendale, PA, (1990), 15.

17) L. K. Chiang: Proc. of the Steelmaking Conf., TMS, Warrendale, PA, (1992), 437.

18) R. E. Martinez and T. H. Solis: Proc. of the Steelmaking Conf., TMS, Warrendale, PA, (1992), 893

19) L. Xintian, Z. Yaohe, S. Baolu and J. Weiming: Ironmaking Steelmaking, 19 (1992), 221.

20) Y. Sahai and M. D. Burval: Proc. of the Electric Furnace Conf., TMS, Warrendale, PA, (1992), 469.

21) S. Singh and S. C. Koria: ISIJ Int., 33 (1993), 1228.

22) S. Singh and S. C. Koria: Ironmaking Steelmaking, 20 (1993), 221.

23) S. Singh and S. C. Koria: ISIJ Int., 34 (1994), 784.

24) K. M. Godiwala, S. K. Sinha and C. S. Sivaramkrishnan: Steel Res., 65 (1994), 267.

25) D. Bolger and K. Sailor: Proc. of the Steelmaking Conf., TMS, Warrendale, PA, (1994), 225.

26) K. M. Godiwala, S. K. Sinha and C. S. Shivaramkrishnan: Proc. of the Steelmaking Conf., TMS, Warrendale, PA, (1994), 703.

27) R. W. Crowley and G. D. Lawson: Proc. of the Steelmaking Conf., TMS, Warrendale, PA, (1995), 629.

28) S. Singh and S. C. Koria: Steel Res., 66 (1995), 294.

29) D. Mazumdar, G. Yamanoglu, S. Ramani and R. I. L. Guthrie: Steel Res., 66 (1995), 14.

30) C. Damle and Y. Sahai: ISIJ Int., 36 (1996), 681.

31) D. Mazumdar, G. Yamanoglu and R. I. L. Guthrie: Steel Res., 68 (1997), 293.

32) M. M. Collur, D. B. Love and B. V. Patil: Proc. of the Steelmaking Conf., TMS, Warrendale, PA, (1997), 313.

33) O. Levenspiel: Chemical Reaction Engineering-An introduction to the design of chemical reactors, John Wiley and Sons Inc., New York, (1967), 243.

34) Y. Sahai and T. Emi: ISIJ Int., 36 (1996), 667.

35) T. Debroy and J. A. Sychterz: Metall. Trans., 16B (1985), 497.

36) J. Szekely and N. El-Kaddah: Proc. of the Steelmaking Conf., TMS, Warrendale, PA, (1986), 761.

37) Y. He and Y. Sahai: Proc. of the Steelmaking Conf., TMS, Warrendale, PA, (1986), 745.

38) J. Szekely, O. J. Illegbussi and N. El-Kaddah: Physicochemical Hydrodynamics, 9 (1987), 453.

39) Y. Sahai: Mathematical Modelling of Materials Processing Operations, ed. by J. Szekely et al., TMS, Warrendale, PA, (1987), 431.

40) O. J. Illegbussi and J. Szekely: Mathematical Modelling of Materials Processing Operations, ed. by J. Szekely et al., TMS, Warrendale, PA, (1987), 409.

41) Y. He and Y. Sahai: Metall. Trans., 18B (1987), 81.

42) K. H. Tacke and J. C. Ludwig: Steel Res., 58 (1987), 262.

43) O. J. Illegbussi and J. Szekely: Steel Res., 59 (1988), 399.

44) O. J. Illegbussi and J. Szekely: Ironmaking Steelmaking, 16 (1989), 110.

45) O. J. Illegbussi and J. Szekely: ISIJ Int., 29 (1989), 1031.

46) S. Joo and R. I. L. Guthrie: Can. Metall. Q., 30 (1991), 261.

47) A. Gaston, R. Laura and M. Medina: Ironmaking Steelmaking, 
$18(1991), 370$.

48) S. Chakraborty and Y. Sahai: Metall. Trans., 22B (1991), 429.

49) O. J. Illegbussi and J. Szekely: Steel Res., 62 (1991), 193

50) M. Sillanpaa: Proc. of the Steelmaking Conf., TMS, Warrendale, PA, (1992), 899.

51) S. Chakraborty and Y. Sahai: Ironmaking Steelmaking, 19 (1992), 479.

52) S. Chakraborty and Y. Sahai: Ironmaking Steelmaking, 19 (1992), 488.

53) S. Chakraborty and Y. Sahai: Metall. Trans., 23B (1992), 153.

54) S. Joo, J. W. Han and R. I. L. Guthrie: Metall. Trans., 24B (1993), 767.

55) S. Joo, J. W. Han and R. I. L. Guthrie: Metall. Trans., 24B (1993), 779 .

56) A. K. Sinha and Y. Sahai: ISIJ Int., 33 (1993), 556.

57) B. Kaufman, A. Neidermay and A. Preuer: Steel Res., 64 (1993), 203.

58) O. J. Illegbussi: ISIJ Int., 34 (1994), 732.

59) C. Damle and Y. Sahai: Trans. ISS, 16 (1995), 49.

60) B. E. Launder and D. B. Spalding: Computer Methods in Applied Mechanics and Engg., 3 (1974), 269.

61) M. C. Gunton, H. I. Ronsten, D. B. Spalding and D. G. Tatchell: PHOENICS instruction manual, CHAM technical report/75, (1983).

62) A. W. Cramb and M. Byrne: Iron Steelmaker, 5 (1986), 27.

63) J.-L. Yeh, W.-S. Hwang and C.-L. Chou: Ironmaking Steelmaking, 19 (1992), 501.

64) M. L. Lawry and Y. Sahai: Proc. of the Steelmaking Conf., TMS, Warrendale, PA, (1989), 71.

65) T. Robertson and A. Perkins: Ironmaking Steelmaking, 13 (1986),
301.

66) R. D. Morales, M. A. Barron Mea, J. J. Barrette and A. W. D. Hills: Proc. of the Steelmaking Conf., TMS, Warrendale, PA, (1997), 325.

67) D. Y. Sheng, C. S. Kid, J. K. Yon and T. C. Hsiao: ISIJ Int. 38 (1998), 844.

68) K. Y. M. Lai, M. Salcudean, S. Tanaka and R. I. L. Guthrie Metall. Trans., 17B (1986), 449.

69) O. J. Illegbussi, J. Szekely, R. Boom, A. Van der Heiden and J. Klootwijk: Proc. of the W. O. Philbrook Memorial Symposium, TMS, Warrendale, PA, (1988), 185.

70) S. Joo, R. I. L. Guthrie and C. J. Dobson: Proc. of the Steelmaking Conf., (1989), 401.

71) J. M. Camplin, J. Herbertson, H. Holl, P. Whitehouse, R. I. L. Guthrie, J. W. Han and M. Hassan: Proc. of the Sixth Int. Iron and Steel Cong., ISIJ, Tokyo, 3 (1990), 207.

72) S. M. Lee, Y. S. Koo, T. Kang, I. R. Lee and Y. K. Shin: Proc. of the Sixth Int. Iron and Steel Cong., ISIJ, Tokyo, 3(1990), 239.

73) S. Joo and R. I. L. Guthrie: Metall. Trans., 24B (1993), 755.

74) H. Chen and R. D. Pehlke: Proc. of the Steelmaking Conf., TMS, Warrendale, PA, (1994), 695.

75) C. Damle and Y. Sahai: ISIJ Int., 35 (1995), 163.

76) G. A. Brooks and W. Setiadharmaji: Proc. of the Steelmaking Conf., TMS, Warrendale, PA, (1997), 655.

77) J. J. Barreto-Sandoval, A. W. D. Hills, M. A. Barron-Mea, R. D. Morales and J. J. Uribe-Galan: Proc. of the Steelmaking Conf., TMS, Warrendale, PA, (1997), 529.

78) J. Madius, D. Martin, F. Ferreyra, R. Villoria, C. Cesar and R. Ferran: Proc. of the 81st Steelmaking Conf., (1998), 73. 